\title{
Performance and evaluation of a coupled prognostic model TAPM over a mountainous complex terrain industrial area
}

\author{
Vasileios N. Matthaios $^{1,2}$ • Athanasios G. Triantafyllou ${ }^{1}$ - Triantafyllos A. Albanis ${ }^{3}$ • \\ Vasileios Sakkas $^{3} \cdot$ Stelios Garas $^{1}$
}

Received: 20 January 2016 / Accepted: 6 April 2017 / Published online: 28 April 2017

(C) The Author(s) 2017. This article is an open access publication

\begin{abstract}
Atmospheric modeling is considered an important tool with several applications such as prediction of air pollution levels, air quality management, and environmental impact assessment studies. Therefore, evaluation studies must be continuously made, in order to improve the accuracy and the approaches of the air quality models. In the present work, an attempt is made to examine the air pollution model (TAPM) efficiency in simulating the surface meteorology, as well as the $\mathrm{SO}_{2}$ concentrations in a mountainous complex terrain industrial area. Three configurations under different circumstances, firstly with default datasets, secondly with data assimilation, and thirdly with updated land use, ran in order to investigate the surface meteorology for a 3year period (2009-2011) and one configuration applied to predict $\mathrm{SO}_{2}$ concentration levels for the year of 2011.The modeled hourly averaged meteorological and $\mathrm{SO}_{2}$ concentration values were statistically compared with those from five monitoring stations across the domain to evaluate the model's performance. Statistical measures showed that the surface temperature and relative humidity are predicted well in all three simulations, with index of agreement (IOA) higher than 0.94 and 0.70 correspondingly, in all monitoring sites, while an overprediction of extreme low temperature values is noted, with mountain altitudes to have
\end{abstract}

Vasileios N. Matthaios

vmatthaios@gmail.com

1 Department of Environmental Engineering and Pollution Control, Laboratory of Atmospheric Pollution and Environmental Physics, Technological Educational Institution (TEI) of Western Macedonia, 50100 Kozani, Greece

2 Present address: School of Geography, Earth and Environmental Sciences, University of Birmingham, Birmingham B15 2TT, UK

3 Department of Chemistry, Laboratory of Environmental Technology, University of Ioannina, 45110 Ioannina, Greece an important role. However, the results also showed that the model's performance is related to the configuration regarding the wind. TAPM default dataset predicted better the wind variables in the center of the simulation than in the boundaries, while improvement in the boundary horizontal winds implied the performance of TAPM with updated land use. TAPM assimilation predicted the wind variables fairly good in the whole domain with IOA higher than 0.83 for the wind speed and higher than 0.85 for the horizontal wind components. Finally, the $\mathrm{SO}_{2}$ concentrations were assessed by the model with IOA varied from 0.37 to 0.57 , mostly dependent on the grid/monitoring station of the simulated domain. The present study can be used, with relevant adaptations, as a user guideline for future conducting simulations in mountainous complex terrain.

\section{Introduction}

Atmospheric models are routinely used in several regions around the globe in order to study the air quality and/or apply environmental friendly policies. These models are also useful as decision support systems in cases of pollution episodes (e.g., San Jose et al. 2005) and/or accidents in industrial or other facilities. The atmospheric air quality models can roughly be categorized depending on the approach they follow into: Box models, Gaussian models, Eulerian models, Lagrangian models, and computational fluid dynamic (CFD) models (Russell and Dennis 2000; Seaman 2000). The Box model is the simplest approach, which uses an algorithm that assumes that the air is shed in the shape of a homogenous box (e.g., Lettau 1970). Box models are used for studies focusing on atmospheric chemistry alone; however, they lack significant physical realism (e.g., horizontal and vertical transport, spatial variation, etc., Russell and Dennis 2000). The Gaussian models are the most common models in use, as they assume 
that the dispersion of pollutants by the wind is made according to the normal statistical distribution (e.g., ISCST3, AERMOD, US EPA 1995, 2004). These types of models are computationally fast, but they need meteorological information about the region of interest, which includes surface-based and/or profiles of winds and temperature. An alternative approach in the absence of measurements is the model coupling (e.g., Triantafyllou and Kassomenos 2002; Moussiopoulos et al. 2004). In addition, it must be mentioned that the chemical processes in Gaussian-type models are either ignored or treated with the simplest form. The Eulerian models include both single box models and multi-dimensional grid-based air quality models. They solve the governing equations for each cell of the simulation by dividing the modeling region into a large number of cells, horizontally and vertically, to simulate the various processes that influence the pollutants' concentrations, including chemistry, diffusion, advection, and deposition (wet and dry). Lagrangian models are used to represent the dispersion of pollutants based on a reference point/grid by the prevailing wind or the direction of the dust plume. Lagrangian models are appropriate for the simulation of stack emissions, provided that the user is aware of the number of released particles from the stack, as well as the size distribution of pollutants. Lastly, the CFD models apply an integrated approach to the model domain by solving the Navier-Stokes partial differential equation system by using state-of-the-art numerical methods. In addition, they are considered suitable for representing more complex flows such as those that may develop in open-pit mines (Silvester et al. 2009). A review about the recent techniques in CFD models can be found in Tominaga and Stathopoulos (2013).

One major fact that concerns the scientific community, however, is the validity of the results of the aforementioned models and how they can represent the reality in urban areas and/or complex terrain. Another continuously debating issue is that the measurements used for the model's evaluation are usually case-dependent and thus potential errors and/or biases are not revealed in such cases. Practically, the evaluation of the model is the ability of the latter to reproduce an observed situation; thus, no absolute criteria can exist whether the model can be characterized as successful or not, for a variety of reasons. One precondition for such an evaluation is the reliability of the experimental data that are used for the evaluation, while another can be their representativeness. Therefore, all measured parameters in a dataset should be supplemented with their estimated error and/or uncertainty, both statistical and systematic, which must be taken into consideration during the evaluation procedure. Unfortunately, for a non-casedependent evaluation, including the present one, such information is not available. For that reason, in our case, the observations are assumed to represent the "reality" and comments and discussions are given in cases when their reliability or representativeness is questioned. Several scientists have addressed this issue of the evaluation of the models, both in case-dependent and non-case-dependent evaluations (e.g., Papalexiou and Moussiopoulos 2006; Sokhi et al. 2006; Shiang-Yuh et al. 2008; Srinivas et al. 2011). A recent stepby-step review about the techniques applied for characterizing the model's performance, by identifying the key features so that the modelers can make a suitable choice for their situation, can be found in Bennett et al. (2013). Furthermore, tools to evaluate in a qualitative and quantitative way the atmospheric models, applicable in several modeling software, have also been developed recently (e.g., Appel et al. 2011).

This paper focuses on the evaluation of the performance of the air pollution model (TAPM) in the region of Western Macedonia, Greece. Despite some attempts to evaluate TAPM in a mountainous terrain (Triantafyllou et al. 2011; Aidaoui et al. 2014; Matthaios et al. 2016), from the current bibliography and as far as the authors are aware, this is the first detailed and long-term attempt to evaluate TAPM in a mountainous complex terrain area. However, there have been several studies concerning the model's performance in a coastal and/or flat terrain. More specifically, Luhar and Hurley (2003) applied and evaluated TAPM for two tracer cases over a flat terrain, and they compared the results with several other models. They found that TAPM performs equally well as the best of these models, even in extreme concentration statistics. In another study, where TAPM was applied to predict hourly urban air pollution concentrations, it was found that the model is capable of predicting the yearlong smog and particle concentrations well both with and without data assimilation (Hurley et al. 2003). In addition, concerning the evaluation of TAPM in a coastal region, in a study made by ZawarReza et al. (2005a), it was found that TAPM performs well with good statistical indices for meteorology and pollution; however, the authors also found that TAPM tends to overestimate surface wind speed over urban areas during stagnant nocturnal conditions. This particular study attempts to examine the model's performance for the wind flow, meteorology, and updated land use and pollution in the mountainous complex terrain area of Western Macedonia in Greece. In detail, simulations were carried out for three continuous years (2009, 2010, and 2011) for meteorology under specific circumstances, with the intention of investigating the model's performance with and without data assimilation, as well as with updates in land use. Moreover, a comparison of the modeled and observed data was made and the frequencies of the local circulations from the lake breeze as well as from mountain flows were also presented and compared. Section 2 of the paper describes briefly the area under investigation. In Section. 3, a brief outline of the model and the prescribed configurations for the simulations are illustrated, while a reference to the statistical measures used for this occasion is also made. Section 4 describes the results both in qualitative and quantitative way, with plots and the statistical indices that 
were used and compares the results from the model performances with observations at the monitoring sites in the area. Finally, in Section. 5, the conclusions of this work are given.

\section{Site description}

The area that was simulated in this study covers the geographical axis of Amyntaio-Ptolemaida-Kozani basin (APKB), which is a mountainous complex terrain area of Western Macedonia, located in the Northwestern part of Greece. It is characterized as broad, relatively flat-bottom basin surrounded by tall mountains with heights from $600 \mathrm{~m}$ to more than $2000 \mathrm{~m}$ above mean sea level. More particularly, in the eastern sides of the area, located are the tall mountains of Voras $(2525 \mathrm{~m})$ and Vermio $(2100 \mathrm{~m})$, while in the western sides, situated are the tall mountains of Vitsi (2128 m), Askio (2111 m), and Burinos (1866 m), and in the southern part are the mountains of Pieria $(2190 \mathrm{~m})$. APKB is approximately $50 \mathrm{~km}$ in length and the width ranges from $10 \mathrm{~km}$ (center part) to $25 \mathrm{~km}$ (boundaries), and it has also sloping terrain geometry of $2^{\circ}$ every $1050 \mathrm{~m}$ from south to north. The sides of the basin are covered with wooded lands, isolated trees, scrubs, and sparse vegetation. Furthermore, in the south part of the basin, the artificial lake of Polifitos is located, which is about $3 \mathrm{~km}$ wide and $25 \mathrm{~km}$ long. This lake together with the four natural lakes of Petron, Vegoritida, Ximaditida, and Zazari in the north and northwest part characterizes the topography as fairly complex.

The area can be categorized as a heavily industrialized area, since four lignite power plant stations (PPS) of $4000 \mathrm{MW}$ in total (Fig. 1) operate in the basin, producing the greatest amount of the total electrical energy produced in Greece. The lignite used by these PPSs is mined in the nearby open-pit mines and transported to the stations via a network of trucks and conveyor belts. One lignite power station 675 MW (PPS5) also operates in Bitola/FYROM, close to the border of the area of interest. In particular, the most significant emissions arising from the combustion of lignite and from mining of the lignite coal, as well as from the transport of lignite ash, are mainly particles (fly ash and fugitive dust) and sulfur dioxide $\left(\mathrm{SO}_{2}\right)$ (Triantafyllou and Kassomenos 2002).

The climate of the area is continental Mediterranean with low temperatures during winter and high ones during summer, signifying rather strong temperature inversions during the whole year (Triantafyllou et al. 1995). The prevailing blowing winds in the center of the basin are weak to moderate and are mostly from the NW/SE direction due to channeling of the synoptic wind, since the NW/SE axis coincides with the major geographical axis of the basin (Triantafyllou 2001, 2003). In the basin, more than 150,000 people live and work mainly in the two major

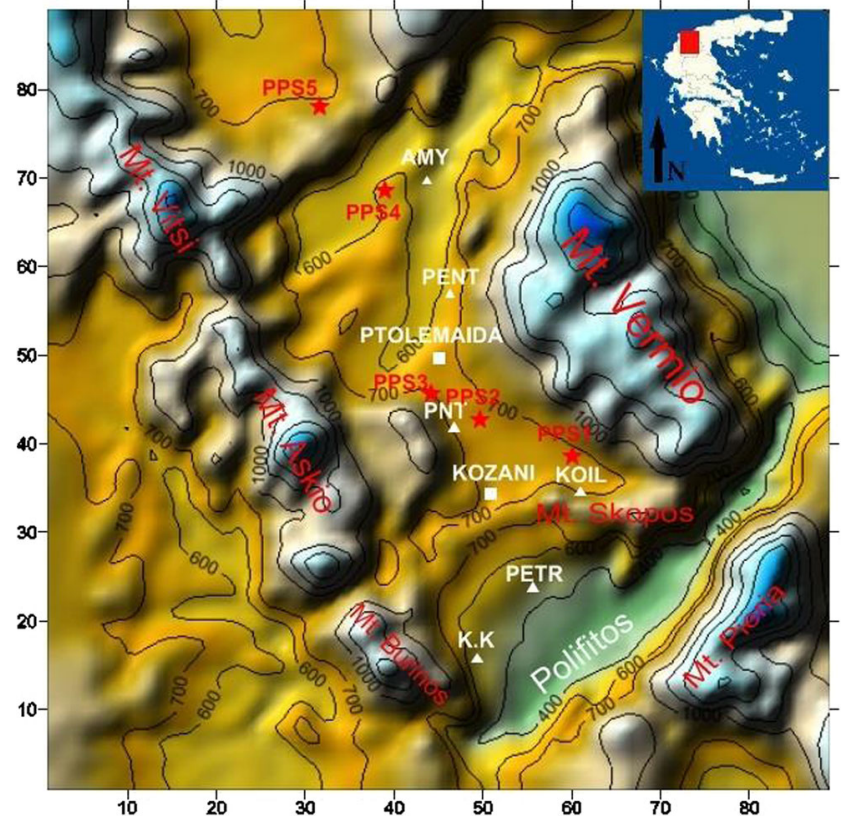

Fig. 1 Topography of the APKB greater area showing the power plant stations in the region (PPS1 to PPS5). PS3, the oldest PS, stopped operating since 2014. The two major cities (white square, Kozani and Ptolemaida) and the monitoring stations (white triangle) used in this study are also showed as well as the artificial lake of Polifitos and the major mountains. Elevations are in meters

towns of Kozani and Ptolemaida, with about 60,000 and 40,000 inhabitants, respectively. There are also several villages with populations ranging from numerous 100 s to 1000 s of inhabitants. Figure 1 below depicts the topography of the investigated area, including the two major cities, the power plant stations (PPS), as well as the peripheral monitoring stations that were used for this study.

\section{Model overview and simulation details}

\subsection{Overview of the model TAPM}

The air pollution model (TAPM) developed by Commonwealth Scientific and Industrial Research Organization (CSIRO) is an operational, coupled prognostic meteorological and pollutant dispersion model. It is a three-dimensional (3D) terrain following sigma-coordinate, PC-based, nestable, prognostic meteorological and air pollution model driven by a graphical user interface. It uses global input databases of terrain height, land use, leaf area index, sea-surface temperature, and synoptic meteorological analyses and can be used in one-way nestable mode to improve efficiency and resolution. TAPM uses the fundamental equations of atmospheric flow, thermodynamics, moisture conservation, turbulence, and dispersion, wherever is practical. TAPM also consists of coupled prognostic meteorological and air pollution concentration components, eliminating the need to have sitespecific meteorological observations. For computational 
efficiency, it includes a nested approach for meteorology and air pollution, with the pollution grids optionally being able to be configured for a subregion and/or at finer grid spacing than the meteorological grid, which allows a user to zoom-in to a local region of interest quite rapidly.

More specifically, the meteorological component of TAPM predicts the local-scale flow against a background of larger-scale meteorology provided by input synoptic analyses (or forecasts) that drive the model at the boundaries of the outer grid. It solves momentum equations for horizontal wind components; the incompressible continuity equation for the vertical velocity in a terrain-following coordinate system; and scalar equations for potential virtual temperature, specific humidity of water vapor, cloud water/ice, rain water, and snow. Explicit cloud microphysical processes are included. Pressure is determined from the sum of hydrostatic and optional non-hydrostatic components, and a Poisson equation is solved for the nonhydrostatic component. The non-hydrostatic option is important if there are cases with significant vertical accelerations (e.g., steep terrain, fronts, and deep convection). In this study, we use the hydrostatic option, which is appropriate for the present application and takes into accaunt low winds. Measurements of wind speed and direction can optionally be assimilated into the momentum equations as nudging terms. The turbulence closure terms in the mean equations use a gradient diffusion approach, including a counter-gradient term for the heat flux, with eddy diffusivity determined using prognostic equations for E- $\varepsilon$. A vegetative canopy, soil scheme, and urban scheme are used at the surface, while radiative fluxes, both at the surface and at upper levels, are also included. Surface boundary conditions for the turbulent fluxes are determined via the Monin-Obukhov surface-layer scaling variables and parameterizations for stomatal resistance. The air pollution component of TAPM uses the predicted meteorology and turbulence from the meteorological component and consists of an Eulerian grid-based set of prognostic equations for pollutant concentration and an optional Lagrangian particle mode that can be used on the inner-most nest for pollution from selected point sources to allow a more detailed account of near-source effects, including gradual plume rise. The Lagrangian mode uses Hurley's (1994) PARTPUFF approach, whereby the released mass at a given instant is represented as a circular puff in the horizontal plane, and the vertical motion of this puff is determined via a Lagrangian particle approach. More information about the model's equations and parameterizations, including the numerical methods and a summary of some verification studies, can be found in Hurley et al. 2001; Hurley et al. 2005; Hurley et al. 2008, while the application of the model in light-winds can be found in Luhar and Hurley (2012).

\subsection{Model configurations}

The model's version 4.0.5 ran for 3-year period (2009, 2010 and 2011) in Western Macedonia for meteorology and 1 year (2011) for air pollution. For the meteorology simulations, the model ran with three different configurations (described below in detail) and for air pollution simulations, one configuration was used (also described in detail below). The input synoptic fields of the horizontal wind components, temperature, and moisture required in TAPM for the aforementioned years were derived from the US National Centers for Environmental Prediction (NCEP) reanalysis, which were available on a global scale with a resolution of $2.5^{\circ}$ longitude $\times 2.5^{\circ}$ latitude on 17 pressure levels (the lowest five being 1000, 925, 850, 700, and $600 \mathrm{hPa}$ ) every $6 \mathrm{~h}$ (Luhar and Hurley 2012). For the topography, global terrain height data on a longitude/latitude grid at 30-s grid spacing (approximately $1 \mathrm{~km}$ ) based on public domain data available from the US Geological Survey; Earth Resources Observation Systems (EROS) was used. Soil characterization of the area was derived from the global soil texture types on a longitude/latitude grid at 2-degree grid spacing (approximately $4 \mathrm{~km}$ ) based on FAO/UNESCO soil classes dataset. As far as the meteorological simulations are concerned, three configurations were made as already mentioned above. The first configuration with the default datasets of the model (TAPM-D) ran for a 3 -year period with three nested grid domains of $45 \times 45$ horizontal grid points at 18,6 , and $2 \mathrm{~km}$ (see Fig. 2). The vertical levels of the model are fixed and ranging from 10 to $8 \mathrm{~km}$. In the current study, we selected 25 vertical levels to capture the synoptic circulation at $10 \mathrm{~m}, 25 \mathrm{~m}, 50 \mathrm{~m}, 100 \mathrm{~m}, 150 \mathrm{~m}$, $200 \mathrm{~m}, 250 \mathrm{~m}, 300 \mathrm{~m}, 400 \mathrm{~m}, 500 \mathrm{~m}, 600 \mathrm{~m}, 750 \mathrm{~m}, 1 \mathrm{~km}$, $1.25 \mathrm{~km}, 1.5 \mathrm{~km}, 1.75 \mathrm{~km}, 2 \mathrm{~km}, 2.5 \mathrm{~km}, 3 \mathrm{~km}, 3.5 \mathrm{~km}, 4 \mathrm{~km}$, $5 \mathrm{~km}, 6 \mathrm{~km}, 7 \mathrm{~km}$, and $8 \mathrm{~km}$. For this model configuration, $147 \mathrm{~h}$ were required for the integration of the run on an Intel(R)Core(TM)2DuoCPU E8400@3.00GHz, 1.96GB RAM. The selected outputs for this run were five monitoring stations in order to cover the whole latitude and longitude of the area, named as Amyntaio (AMY), Pentavrysos (PENT), Pontokomi (PONT), Kato Komi (K.KOMI), and Koilada (KOIL) (see Figs. 1 and 2). The second configuration (TAPM-A) was made by adding an additional parameter, data assimilation in winds, for four places (AMY, PENT, PNT and K.KOMI), while keeping all the other parameters (vertical levels, domains, grid spacing, synoptic datasets, topography, and land use) unchanged. It should be mentioned here that although KOIL station was selected as output in this run, no assimilation was inputted. The exclusion of data assimilation for this monitoring station was made on purpose. The intension was to see the influence of data assimilation in the results of predicted winds from the model in a monitoring site which is affected not only from mountain flows but also from terrain's rotated winds. The second simulation took $162 \mathrm{~h}$ of run 
Fig. 2 a Grid domains of the simulation. b Inner grid of the simulation (2-km resolution) depicting the topography of the area as well as the monitoring stations. Elevations are in meters

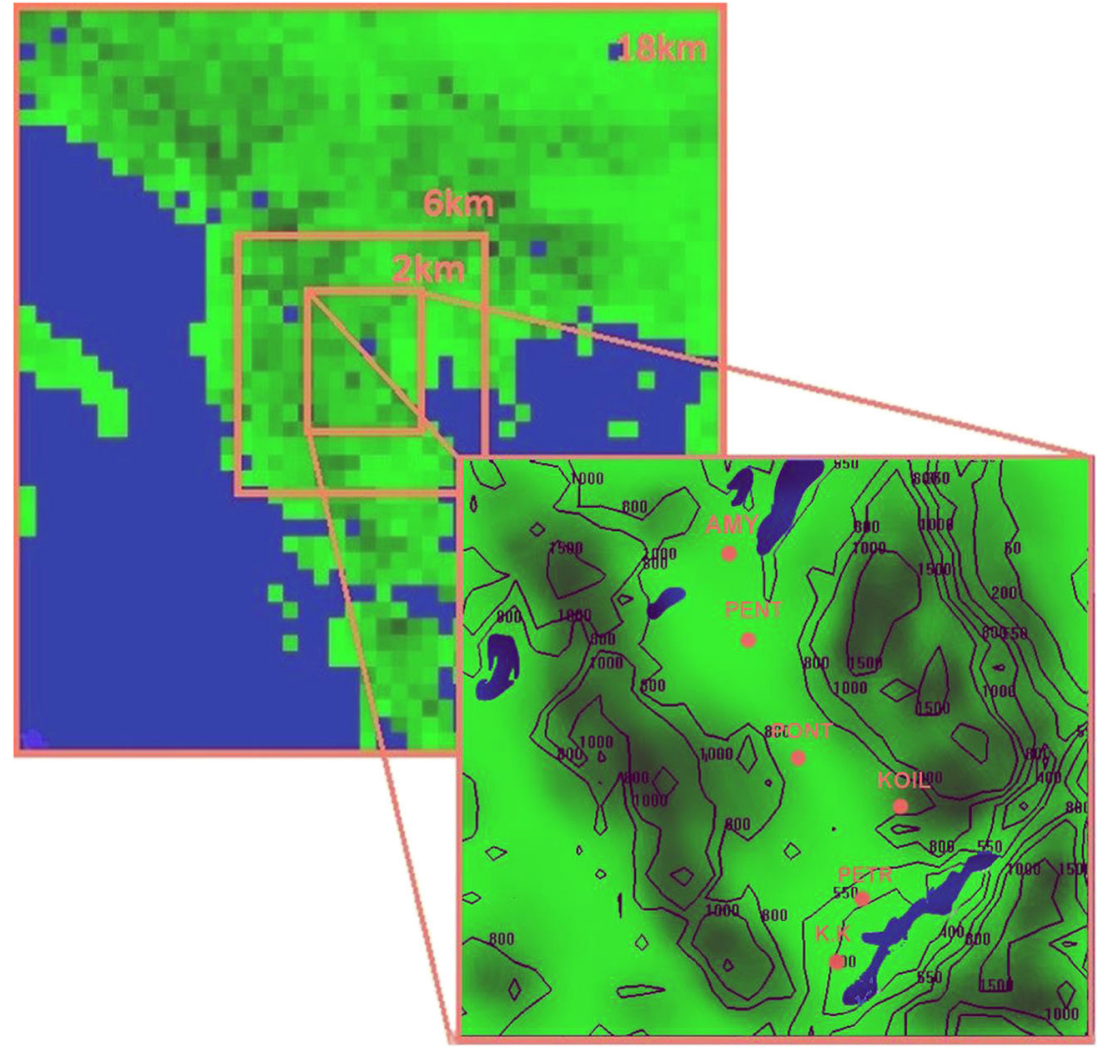

time in the same hardware. The third configuration (TAPMLU) was made by applying updates in land use to the innermost grid domain (2-km resolution) while keeping the other characteristics the same as the default configuration without data assimilation. The basic modified variables that were changed in TAPM-LU were the vegetation roughness length with values $0.55 \mathrm{~m}$ (Forests -low sparse, woodland), $0.06 \mathrm{~m}$ (Grassland, mid-dense tussock), and $0.045 \mathrm{~m}$ (Pasture/herbfield, mid-dense, seasonal), while for urban and industrial categories (wherever added), the roughness length that was chosen was 1 and $1.5 \mathrm{~m}$ and the anthropogenic heat flux $\mathrm{A}_{\mathrm{u}}$ was 30 and $150 \mathrm{Wm}^{-2}$ respectively. The types for the land use/ vegetation are based on Graetz (1998), while the chosen urban category can be regarded as one of medium-density urban conditions, with parameters specified by Oke (1988). The above changes were considered necessary since industrial activity of the PPSs and restored areas from the nearby open-pit mines, as well as the most populated city (Kozani), are not included in the default land use database. Figure 3 depicts the updates in land use characterization that was made for this configuration. The completion of this simulation required the same run time $(147 \mathrm{~h})$ as the default configuration. The pollution configuration had the same horizontal and vertical grid spacing as the above three meteorological configurations, and for pollution/dispersion, the horizontal points were $77 \times 113$ at 9-, 3-, and 1-km spacing (note that pollution grid can be a nested subset to the meteorological grid at finer grid spacing). Eleven stacks from the four power plants in the area were selected as pollution sources, while Lagrangian plus Eulerian approaches were also selected to represent the dispersion near the sources more accurately. In the Lagrangian mode, the travel time of particles before conversion to Eulerian mode was $900 \mathrm{~s}$ (default value). This value is long enough to allow the maximum ground level concentration from elevated point sources to be represented by the Lagrangian particle module, while keeping the run time to a minimum. As already stated above in the area, there are several other sources (e.g., open pit mines) emitting uncontrolled fugitive dust emissions in the atmosphere (Triantafyllou 2000, Samara 2005). Thus, this study focuses on the $\mathrm{SO}_{2}$ which is considered to be mainly emitted from power plants rather than the open-pit mines, representing a rather "tracer-gas" pollutant. Table 1 illustrates the stack characteristics that were used for the simulation. Emission rates are a critical parameter regarding the air-pollution simulations. The available emission rates in our study were average daily values, which were taken by the Greek Public Power Corporation from measurements made in stacks. The model has two options for the simulation of the emission rates: constant and cycled. In this study, the second option was chosen $(216 \mathrm{~h})$ for the air-pollution simulations and practically repeated 41 times in order to cover 1 year of simulation. From the data available, the emissions 
a)

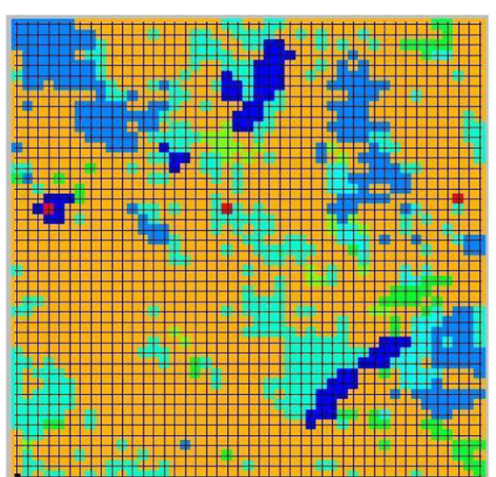

Fig. 3 a Land use cover in TAPM from default database USGS. b Updated land use cover in TAPM. Definition of colors: orange: pasture-mid-dense (seasonal), blue: water, light-blue: forest-mid-dense,

from the power plants were variable and mainly dependent on the demand of the energy consumption. Furthermore, it was also observed from the data that there were days where not all the stacks were in operation due to maintenance and therefore the second option was preferred (hourly) over the first one (constant). The simulations for pollution were carried out with 1-day spin up, while the duration of each run lasted about $47 \mathrm{~h}$.

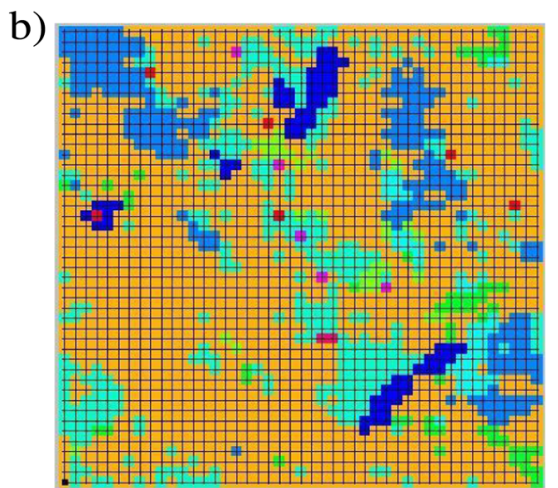

turquoise: forest-low sparse (woodland), light-green: grassland-middense tussock, red: urban, pink: industrial

\subsection{Model performance indices}

Statistical measures for model evaluation are of great importance, because they reveal both to the user and the developer of the model potential errors and biases. Such statistical measures are proposed by several researchers (e.g., Willmott 1981, Pielke 1984, Hanna 1989, Hanna and Chang 2012) in order to evaluate the model's
Table 1 Stack's characteristics included in the simulation of pollution

\begin{tabular}{|c|c|c|c|c|c|}
\hline & & Height (m) & Radius (m) & Exit temperature $(\mathrm{K})$ & Exit velocity $(\mathrm{m} / \mathrm{s})$ \\
\hline \multirow[t]{6}{*}{ PPS1 } & \multirow[t]{2}{*}{ Stack 1} & \multirow[t]{2}{*}{200} & \multirow[t]{2}{*}{4.6} & \multirow[t]{2}{*}{423} & $19^{\mathrm{a}}$ \\
\hline & & & & & $24^{\mathrm{b}}$ \\
\hline & \multirow[t]{2}{*}{ Stack 2} & \multirow[t]{2}{*}{200} & \multirow[t]{2}{*}{4.6} & \multirow[t]{2}{*}{423} & $19^{\mathrm{a}}$ \\
\hline & & & & & $24^{\mathrm{b}}$ \\
\hline & \multirow[t]{2}{*}{ Stack 3} & \multirow[t]{2}{*}{200} & \multirow[t]{2}{*}{4.6} & \multirow[t]{2}{*}{423} & $19^{\mathrm{a}}$ \\
\hline & & & & & $24^{\mathrm{b}}$ \\
\hline \multirow[t]{8}{*}{ PPS2 } & \multirow[t]{2}{*}{ Stack 1} & \multirow[t]{2}{*}{200} & \multirow[t]{2}{*}{3.2} & \multirow[t]{2}{*}{415} & $14.6^{\mathrm{a}}$ \\
\hline & & & & & $16.1^{\mathrm{b}}$ \\
\hline & \multirow[t]{2}{*}{ Stack 2} & \multirow[t]{2}{*}{200} & \multirow[t]{2}{*}{3.2} & \multirow[t]{2}{*}{415} & $14.6^{\mathrm{a}}$ \\
\hline & & & & & $16.1^{\mathrm{b}}$ \\
\hline & \multirow[t]{2}{*}{ Stack 3} & \multirow[t]{2}{*}{200} & \multirow[t]{2}{*}{3.2} & \multirow[t]{2}{*}{415} & $18.5^{\mathrm{a}}$ \\
\hline & & & & & $19.8^{\mathrm{b}}$ \\
\hline & \multirow[t]{2}{*}{ Stack 4} & \multirow[t]{2}{*}{200} & \multirow[t]{2}{*}{3.2} & \multirow[t]{2}{*}{415} & $18.5^{\mathrm{a}}$ \\
\hline & & & & & $19.8^{\mathrm{b}}$ \\
\hline \multirow[t]{6}{*}{ PPS3 } & \multirow[t]{2}{*}{ Stack 1} & \multirow[t]{2}{*}{115} & \multirow[t]{2}{*}{3.6} & \multirow[t]{2}{*}{495} & $15^{\mathrm{a}}$ \\
\hline & & & & & $15.2^{\mathrm{b}}$ \\
\hline & Stack 2 & 115 & 3.6 & 495 & $15.3^{\mathrm{a}}$ \\
\hline & & & & & $15.6^{\mathrm{b}}$ \\
\hline & Stack 3 & 150 & 4.6 & 495 & $15.2^{\mathrm{a}}$ \\
\hline & & & & & $15.2^{\mathrm{b}}$ \\
\hline PPS4 & Stack 1 & 200 & 4.6 & 422 & $14^{\mathrm{a}}$ \\
\hline & & & & & $18^{\mathrm{b}}$ \\
\hline
\end{tabular}

Source: Greek Power Public Corporation (2011, personal communication)

${ }^{a}$ Average value January-May

${ }^{\mathrm{b}}$ Average value July-December 
performance. In the present study, the calculated statistics for the TAPM performance for average hourly data are based on the recommendations by Willmott (1981) and Pielke (1984). More specifically, for meteorology, we used Pearson correlation coefficient (Cor) between observed $(\mathrm{O})$ and predicted $(\mathrm{P})$ values, mean value, standard deviation $(\sigma)$, root mean square error $(\mathrm{RMSE})=[\overline{(P-O)}$ $\left.{ }^{2}\right]^{1 / 2}$, index of agreement $($ IOA $)=1-\left[\left(P^{-} O\right)^{2} /(|P-\bar{O}|+\right.$ $\left.|O-\bar{O}|)^{2}\right], \mathrm{SKILL}_{\mathrm{R}}=R M S E / \sigma_{o}$, and SKILL $\mathrm{S}_{\mathrm{V}}=\sigma_{P} / \sigma_{O}$, where $\sigma_{\mathrm{O}}$ and $\sigma_{\mathrm{P}}$ is the standard deviation of observations and predictions, respectively. Especially, the IOA is a measure of how well the predicted variations around the mean observations are represented, with ranges from 0 to 1 , and as reported in the literature, a number greater than 0.5 generally indicates a good prediction (Hurley et al. 2001, P. Zawar-Reza et al. 2005a). As far as pollution statistics are concerned, the applied statistic measures were the same as the meteorological evaluation but also added measures such as Bias $=\bar{O}-\bar{P}$, fractional bias $(\mathrm{FB})=2(\bar{O}-\bar{P}) /(\bar{O}+\bar{P})$, fraction of predictions within a factor of two of the observations (FAC2), and robust highest concentration $(\mathrm{RHC})=C(R)+(\bar{C}-C(R)) \ln$ $[(3 R-1) / 2]$, where $\mathrm{C}(\mathrm{R})$ is the $R$ th highest concentration and $\bar{C}$ is the mean of the top $\mathrm{R}-1$ concentrations. The $\mathrm{RHC}$, is a more robust statistic for judging the performance of the model in simulating the extreme end of the concentration distribution than the actual peak value, mitigating in that way the undesirable influence of unusual events while still representing the magnitude of the maximum concentration (Cox and Tikvart 1990). The value of $R=11$ is used here to include the average of the top ten concentrations, which is considered an acceptance statistic for model performance evaluation (Hanna 1989).

\section{Results and discussion}

\subsection{Prediction of surface meteorology}

TAPM was configured and ran for a 3-year period from 1 January 2009 until 31 December 2011 for meteorology with three different configurations (see Sect. 3.2). The selected outputs were taken at five selected places in order to be compared with the observations. In order to examine the behavior of the modeled winds towards APKB wind roses between the observed and modeled values were constructed for the entire available data (Fig. 4). It is encouraging to note that the model is able to simulate the prevailing flow patterns in all three configurations for all stations apart from the station of KOIL. This exception is attributed, probably, to the fact that the station's location is idiomorphic (see Figs. 1 and 2, for the location).
More specifically, for the station of AMY (northern boundaries), the TAPM-D is able to calculate the prevailing $\mathrm{N}$ flow, with an underestimation of south sector in general and overestimation of NE winds. Data assimilation performance improves the calculated winds for the station significantly. TAPM-A performance predicts the prevailing $\mathrm{N}$ wind and the magnitude of the winds from $\mathrm{E}, \mathrm{SE}$, and $\mathrm{S}$ direction, which were underestimated by the TAPM-D. However, TAPM-A also tends to overestimate NE flows as the TAPM-D. The flow patterns from the third configuration (TAPM-LU) perform likewise the default. For the station of PENT (center of the simulation domain), the TAPM-D simulates the prevailing winds coming from the $\mathrm{N}$ and $\mathrm{S}$ directions and also represents well the magnitudes of NE and SW flows. Nevertheless, the model seems to overestimate for the station the NW flows by $10 \%$ and the $\mathrm{W}$ winds by $5 \%$. For the same station, TAPM-A predicts both the magnitude and the sequences of the dominant $\mathrm{N}$ and $\mathrm{S}$ flows, and a better prediction is evident for the NW flows, which were overestimated by $10 \%$ in TAPM-D. The TAPM-LU winds here have the same behavior as in TAPM-D simulation with a slight improvement in the NE flows. For the station of PONT (center of the simulation domain), TAPM-D predicts both the sequence and the magnitude of the dominant wind for the station which comes mainly from the NW direction. It is worth mentioning that TAPM-D simulates also the N, SE, and S flows for the station, which occur less frequently than NW flows. Yet, the model overestimates the westerly flows as it does in the PENT station. TAPM-A simulation represents better the flow patterns for the station, but still, a slight overestimation of westerly flows by $5 \%$ remains. The third configuration's TAPM-LU flow patterns have the same behavior for the direction as in the simulation of TAPM-D with a slight difference in wind magnitude. On one hand, the reason for the overestimation of westerly wind is not quite clear, since both stations (PENT, PONT) are located in the center part of the basin and there are no physical obstacles to change the direction of the wind. On the other hand, experiments made by a tethered balloon in the area showed the existence of weak westerly flows in the center of the basin mostly above the stagnant calm layer near the surface and mainly after sunset (Triantafyllou et al. 1995). It is also worth mentioning that this calculated westerly flow overestimation was also found by other researchers (see Zawar-Reza et al. 2005a), who applied the model in a coastal complex terrain. Specifically, Zawar-Reza et al. 2005a found that TAPM, instead of calculating calms, produces weak westerly (drainage) winds by gentle sloping. Furthermore, one must also note that other mesoscale numerical models have the similar problems in sloping complex terrains (Zawar-Reza et al. 2005b). As far as the K.KOMI station is concerned (southern boundary), TAPM-D calculates the flow patterns for the station, with an overprediction in the dominant NW flow by about $15 \%$ and a minor underestimation in easterlies 

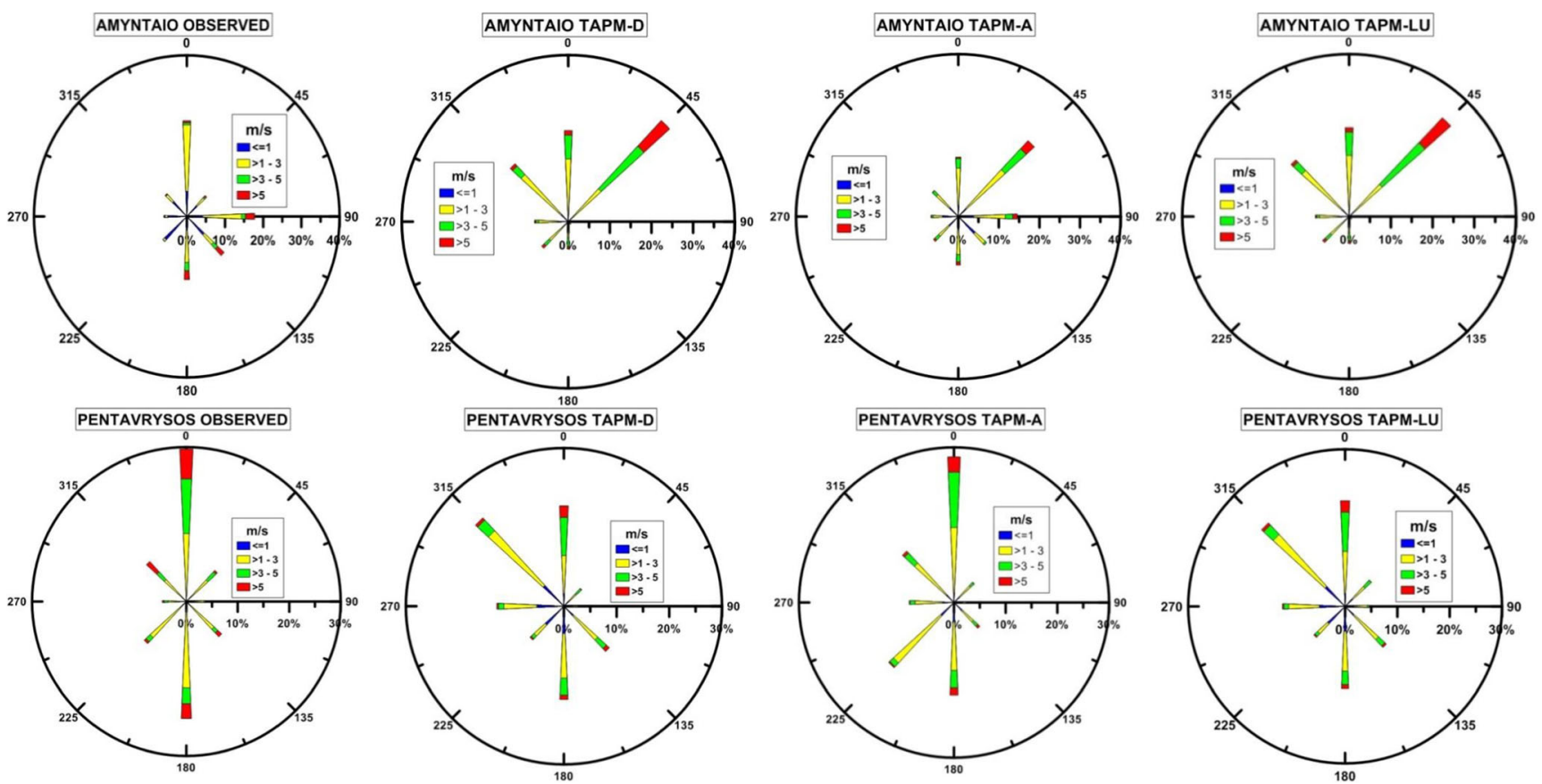

Fig. 4 Wind roses constructed from hourly averaged data for 2009, 2010, and 2011, observed and modeled data by TAPM-D, TAPM-A, and TAPM-LU for the five monitoring sites of the region
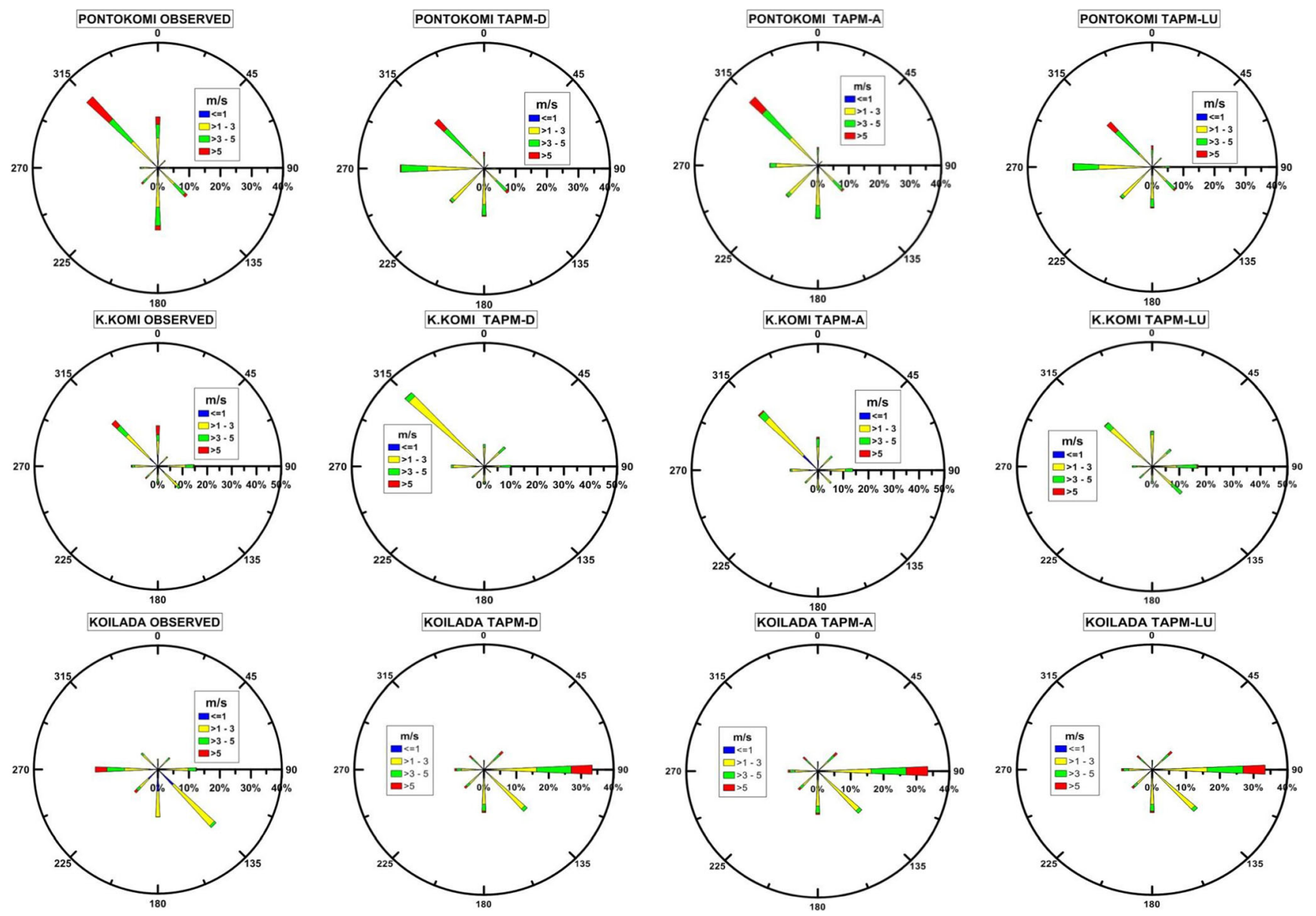

Fig. 4 (continued) 
$(5 \%)$ and SE winds by about $12 \%$. The magnitude of the station's flows is also slightly underestimated by the model. TAPM-A simulation flow patterns display a better calculation than TAPM-D simulation regarding the observed values, with only a slight underprediction in N and SE flows by about $5 \%$. In the last configuration of TAPM-LU, the calculated flow pattern of the station is slightly different from the other two simulations. In detail, TAPM-LU slightly underestimates the $\mathrm{W}$ winds by about $4 \%$, while simultaneously overestimating faintly the SE by about $5 \%$. The station's location is affected by the thermal circulation of the lake of Polifitos (about $5 \mathrm{~km}$ in horizontal distance), and detailed hourly frequencies of winds from observed values against all three simulations are presented in Sect. 4.2. Finally, in the station of KOIL, the TAPM-D performance illustrates an underestimation of the $\mathrm{W}$ flow by $15 \%$. This flow comes from the rotations of the prevailing $\mathrm{N}$ and $\mathrm{NW}$ flow in the center of the basin due to the idiomorphic topography, and it is hard to be calculated. Moreover, as it can be seen from the wind roses TAPM-D overpredicts the E flows. The SE, S, and SW flows are estimated well, with a small underprediction in SE by about $7 \%$. These flows are attributed to orographic flows from the mountains, and detailed frequencies are discussed below in Sect. 4.2. The same behavior occurs in the other two performances of TAPM-A and TAPM-LU.

As far as the surface temperature is concerned, the time series of the hourly averaged temperature between the observed and the calculated values from the three simulations are illustrated in Fig. 5. From this figure, it is rather obvious that the model is able to capture the variations of temperature in all simulations for all the monitoring stations. On the other hand, an overprediction is evident in the extreme low temperatures, which increases in the lower temperatures. Typical winter (February 2009) and summer (June 2010) cases with extreme low and extreme high temperatures are presented in Fig. 6. One reason for this difference maybe has to do with some of the model input parameters. So, soil texture characterization remained default and parameters such as snow, deep soil volumetric moisture constants, and deep soil temperature were unchanged in all simulations (see Sect. 3.2 for configuration details), mainly due to unavailable experimental data. However, such data influence the model's performance and they would rather improve the predicted results. Another possible reason for the difference in the low temperatures is that the temperature is measured in all monitoring stations at about $3 \mathrm{~m}$ AGL, while the predicted values are at $10 \mathrm{~m}$ AGL (first model level). It should be mentioned here that other mesoscale prognostic models reveal differences in temperature both in summer and winter cases in complex mountainous terrains, which in fact are higher than those found in our case (e.g., Seaman et al. 1995, Zhang et al. 2011, De Meij et al. 2009). More particularly, the study of Seaman et al. (1995), who used MM5 in a coastal and mountainous complex terrain (San Joaquin valley) in summer simulations, found that in some cases, local terrain effects (mainly in coastal range ridge areas) can lead to errors in temperature to as much as $10^{\circ} \mathrm{C}$. The more recent study made by Zhang et al. (2011), who also used and evaluated MM5 in China, found that the largest bias in the model's simulated temperature occurred in winter predictions. Zhang et al. (2011) also highlighted that the meteorological predictions of MM5 agree more closely with observations at urban sites than those at coastal and mountain sites where the model performance deteriorates because of complex terrains, influences of urban heat island effect, and land/sea breezes, as well as higher elevations and snow cover. Additionally, De Meij et al. 2009 evaluated MM5 and WRF models in a mountainous complex terrain of Po valley and found that both models underestimate the temperature, and that WRF predicts higher temperature averages than MM5. In our case, the largest difference in hourly extreme low temperatures during winter months was $8.7^{\circ} \mathrm{C}$ in December 2011 (not shown here) in a monitoring station, which has the lowest altitude and it is located close to the artificial lake of Polifitos at about $4.5 \mathrm{~km}$, horizontal distance and close to the mountains of Burinos at about $5.6 \mathrm{~km}$, horizontal distance (K.KOMI). During the winter months, the lake's temperature is warmer than the land's temperature and there is more moisture in the air; therefore, the temperature at night will not have a significant cool down. Nevertheless, the monitoring station is also nearby the tall mountains of Burinos (see Fig. 1, westerly from the monitoring site) with altitude near $1860 \mathrm{~m} \mathrm{AGL}$, and a potential downslope density-driven cold flow in the case when the mountain's ridges are covered with snow might result into this difference in extreme low temperatures. Detailed frequencies in the winds for the monitoring site are depicted and discussed later on (see Sect. 4.2.). The modeled temperature during winter months also differs in the rest of the stations but with smaller modifications regarding the observed temperature. As for the summer extreme high temperatures, the variation of modeled temperature is generally good in most of the monitoring sites. The days, in which there are differences between the observed and simulated temperatures, in all the monitoring sites during the night hours, are due to the quick passage of a surface depression (e.g., 14 and 18 June 2010). However, some almost permanent difference is depicted in PENT monitoring station also in the lower temperatures. The biggest difference was found in July 2010 and it was $7.5^{\circ} \mathrm{C}$. PENT monitoring site is located close to the foothills of the Vermio mountain with the highest altitude in the area, more than $2000 \mathrm{~m}$ AGL (see Fig. 1e from the monitoring site), and a potential downslope flow after the sunset and the rapid cooling of the valley (Triantafyllou et al. 1995) in summer months might result into this difference. The above issues, which indicate the complexity of the simulated terrain, are challenging scientific subjects and address objectives for 


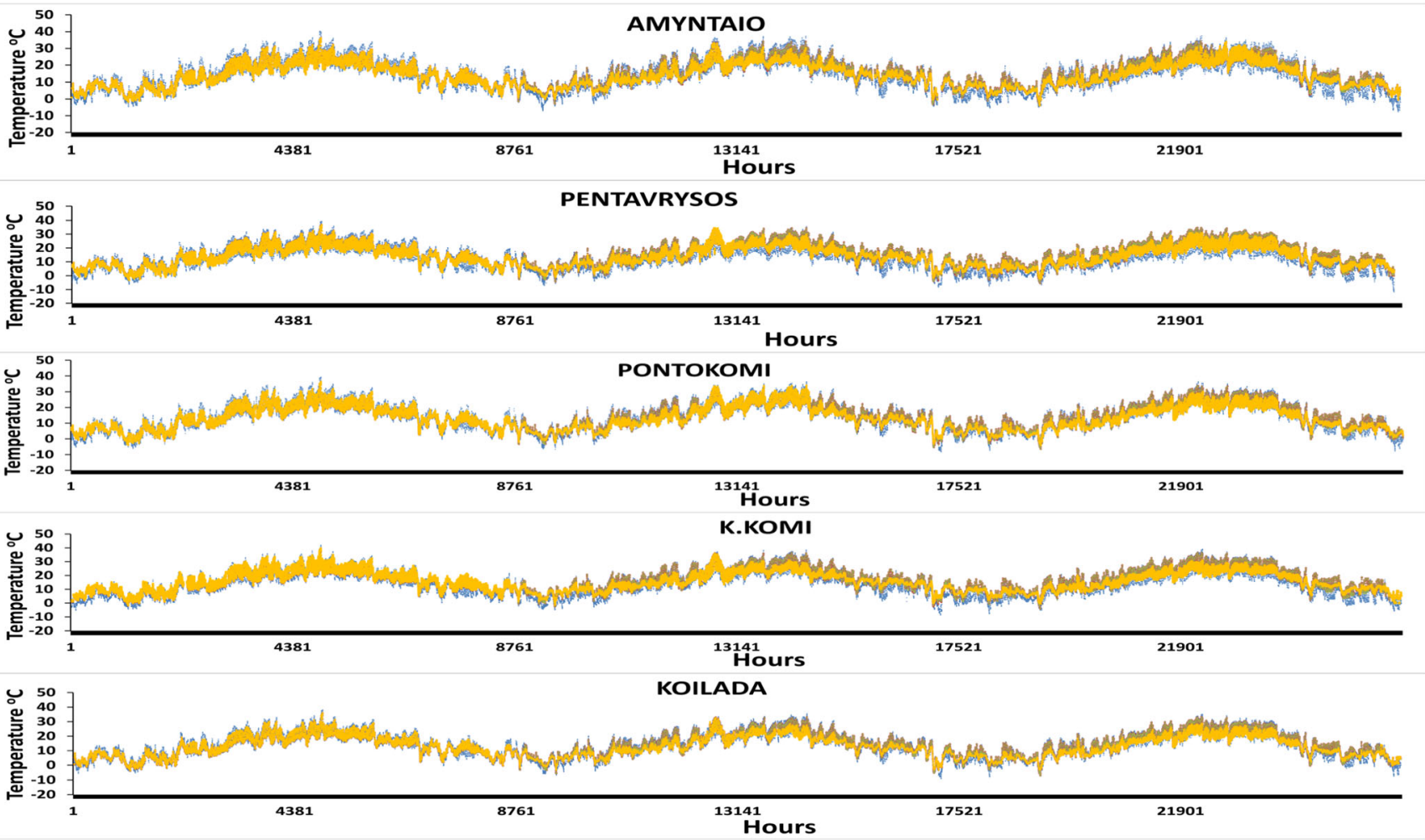

Fig. 5 Time series of the hourly average temperature at $10 \mathrm{~m}$ AGL between observed and predicted values by TAPM-D, TAPM-A, and TAPM-LU for 2009-2011

future work. Evaluation and sensitivity analysis by adding or changing parameters that might influence the model's results (based on measurements) will be made (e.g., deep soil moisture or temperature parameters), and, additionally, numerical simulations and comparison with other prognostic models will be conducted as a part of an additional forthcoming work.

Table 2 presents the statistical performance measures obtained for TAPM-D, TAPM-A, and TAPM-LU using hourly averaged data of wind speed (WS), horizontal wind components $(\mathrm{U}, \mathrm{V})$, temperature $(\mathrm{T})$, and relative humidity $(\mathrm{RH})$, all at $10 \mathrm{~m} \mathrm{AGL}$, measured for 3-year period at the five aforementioned stations (see Fig. 2 for location). In particular, for the station of AMY, which is located at the north boundaries of the domain, there are differences between the modeled and observed values for the wind speed and wind components $(\mathrm{U}, \mathrm{V})$, with the model to overestimate the mean WS by $1 \mathrm{~m} / \mathrm{s}$. The mean temperature (T) is predicted well and the RMSE is lower than the standard deviation, while IOA $=0.95$ indicates that skill is shown by the model . Temperature scoring a higher IOA is a fairly typical result for TAPM as reported in the literature (Hurley et al. 2001, 2003). The IOA for the winds is near the threshold with scores $0.55,0.49$, and 0.53 for the WS and components $\mathrm{U}$ and V, respectively. For the same station, TAPM-A scores are better. In detail, TAPM-A predicts very well the mean WS of the station with only $0.1 \mathrm{~m} / \mathrm{s}$ difference. The RMSEs are lower than the standard deviations of the observations, and the model shows skill in predicting the WS, as well as the components $(\mathrm{U}, \mathrm{V})$ of the station, a fact which is also verified by the higher correlation coefficient and IOA. The scores for those indices are $>0.71$ (Cor) and $>0.83$ (IOA) for all wind variables. The temperature predictions remained largely unaffected and as good as the TAPM-D. The third simulation (TAPM-LU) scores for AMY are almost the same as TAPM$\mathrm{D}$, with a slight improvement in all statistical measures.

For the station of PENT, which is located in the center of the simulation, TAPM-D estimates the mean WS and wind component V well, with their RMSEs to be lower than their standard deviations and with correlation coefficient values $>0.60$ and IOA $>0.70$. As for component $\mathrm{U}$, the IOA score is at the threshold 0.50 . The other meteorological values of the station $(\mathrm{RH}, \mathrm{T})$ are predicted well by the model, with IOA values 0.73 and 0.95 for relative humidity and temperature, respectively. TAPM-A statistical performance for the same station is enhanced. The correlation coefficient and the IOA are higher than 0.83 and 0.89 for all wind variables, while temperature and relative humidity scores remained almost the same as TAPM-D. In the TAPM-LU, all statistical indices for the station of PENT follow the same pattern as TAPM-D.

The performance of TAPM-D for the station of PONT, which is also located in the center of the simulation domain, illustrates a very good prediction of the mean WS with only $0.1 \mathrm{~m} / \mathrm{s}$ difference. The horizontal wind components are also predicted well. The IOA score for the wind variables is 0.62 

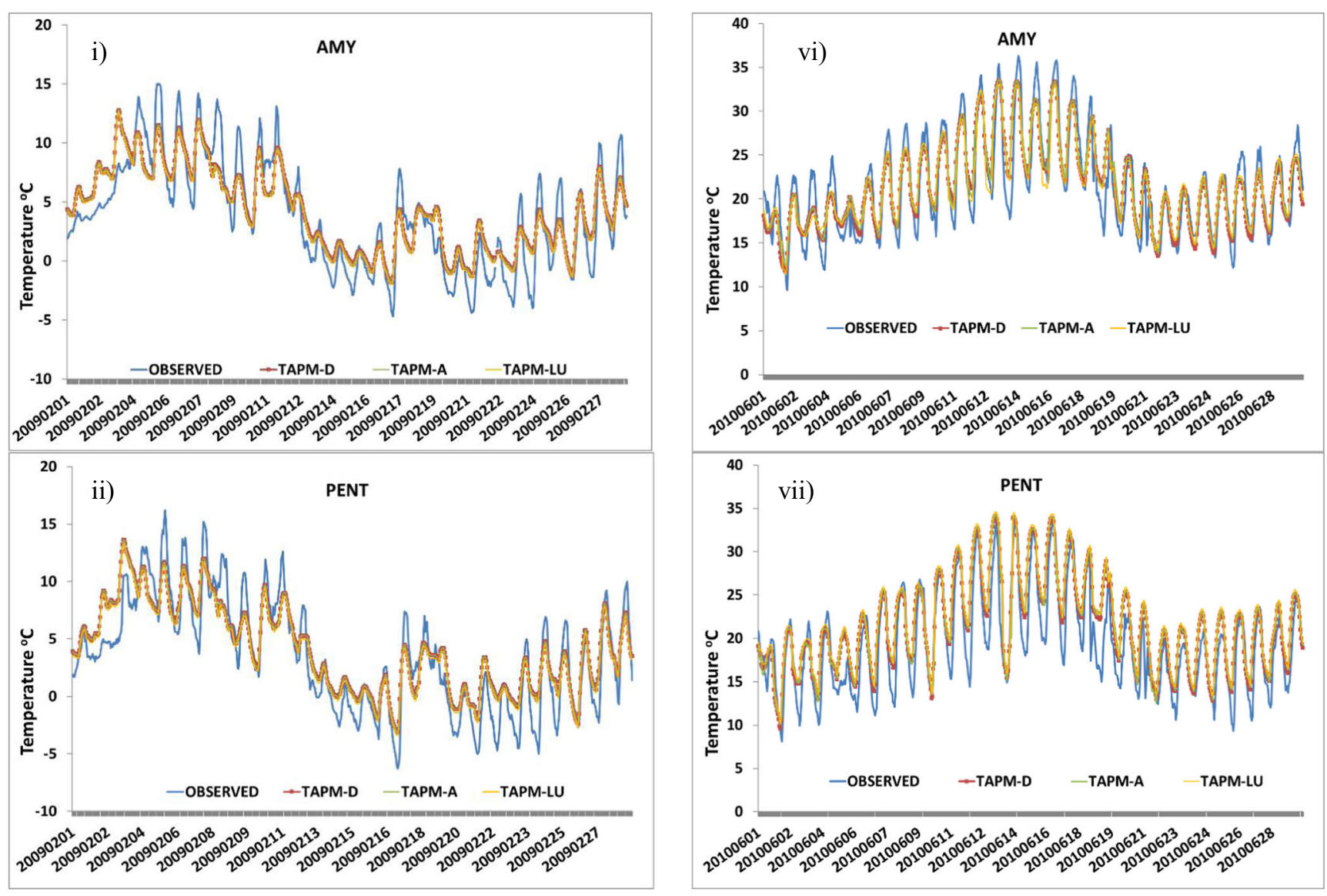

Fig. 6 Hourly averaged time series representing typical cases for the extreme temperature variation in Fig. 5. Plots $i, i i, i i i, i v, v$ are for winter case and $v i$, vii, viii, $i x$ and $x$ are for summer case

(WS), $0.66(\mathrm{U})$, and $0.78(\mathrm{~V})$, while for temperature and relative humidity is 0.98 and 0.77 . The TAPM-A scores are enhanced in all wind predictions, comparing to those by TAPM-D. The model demonstrates better skill, which is also verified by correlation coefficient as well as IOA, with their values being higher than 0.85 and 0.90 for all wind variables, correspondingly. For the meteorological variables of temperature and relative humidity, the model's score was mainly unchanged and as good as the first simulation. For the same station, TAPM-LU performance indicates a light decrease in WS scores, but simultaneously a slight improvement in components $\mathrm{U}$ and $\mathrm{V}$, with the temperature and relative humidity to score the same values with the previous two simulations.

As far as the K.KOMI is concerned, a station which is located close to the southern boundaries of the simulation's domain, TAPM-D, predicts well both the mean WS with $0.4 \mathrm{~m} / \mathrm{s}$ difference and the horizontal component $U$ with $0.1 \mathrm{~m} / \mathrm{s}$ difference. However, an underestimation is evident in the model's performance in predicting the mean horizontal component $\mathrm{V}$, a fact which is also supported by the low correlation coefficient and IOA (0.36, below threshold of 0.5$)$. Temperature and relative humidity scores remain as high as in the other stations with their IOA being 0.96 and 0.74 . TAPM-
A results signify a rather good prediction in all meteorological variables of the station. The scores of IOA are 0.87 and 0.93 for the wind speed and horizontal component $\mathrm{U}$, and particularly component $\mathrm{V}$, which was underpredicted in the previous simulation scores an IOA $=0.92$. TAPM-LU statistical measures show the same scores as TAPM-D for the variables of wind speed, temperature, and relative humidity, and a fair improvement is scored for the horizontal components $\mathrm{U}$ and $\mathrm{V}$. The improvement of the wind components is also verified by the improvement of the correlation coefficient as well as the IOA.

Concerning the station of KOIL, TAPM-D slightly overestimates the mean wind speed by $0.8 \mathrm{~m} / \mathrm{s}$. The IOA is near or at the threshold for all the wind variables, while the scores of temperature and relative humidity are as good as in the other stations. For this station, the other two simulations (TAPM-A and TAPM-LU) generally follow the same statistical patterns and scores as TAPM-D, but as mentioned, no assimilation was included in TAPM-A for this station (see Sect. 3.2.). The SKILL $_{R}$ and SKILL $L_{V}$ are generally within the value limits, while the low SKILL $_{\mathrm{R}} \approx 0.40$ regarding the temperature performance was also found by other verification studies of TAPM (e.g., Hurley et al. 2001; Hurley et al. 2003; Hurley et al. 2005; Zawar-Reza et al. 2005a; Zawar-Reza et al. 

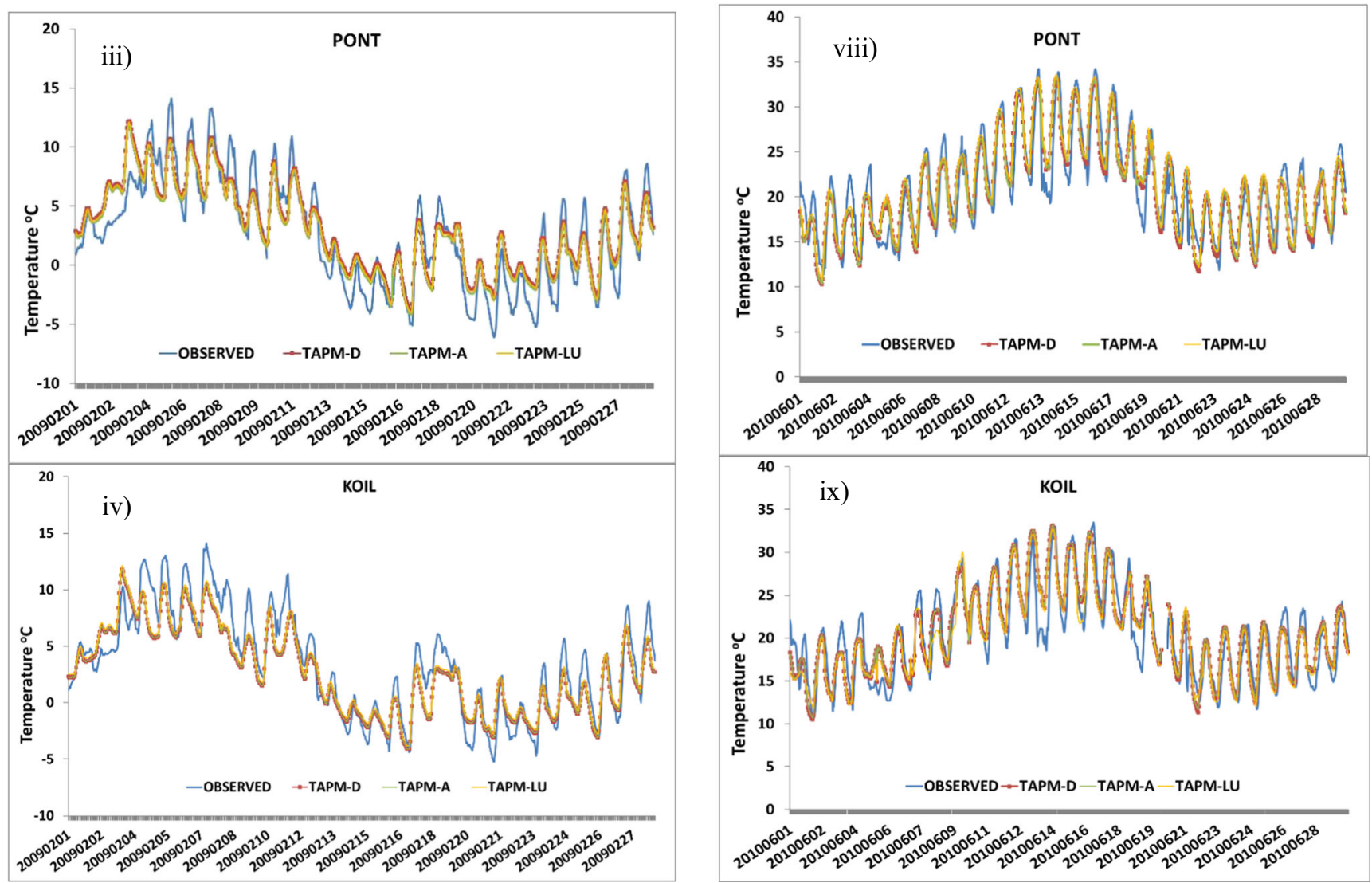

Fig. 6 (continued)

$2005 b)$. In summary, from the hourly average data series and the statistical measures of all three simulations, TAPM is able to predict well the overall surface temperature in all stations of the region. Relative humidity is also predicted well with IOA higher than 0.70 in all simulations. The wind speed and the horizontal components $\mathrm{U}$ and $\mathrm{V}$ are predicted better in the stations located in the center of the simulation, which also score the higher IOA. The stations that are located in the boundaries of the simulation score IOA lower than or at the threshold, a fact which can be improved when data assimilation is included. It should be mentioned here that the above analyses concerning the behavior of the wind variables is in agreement with the grid sensitivity analysis of TAPM made by Zoras et al. 2007, who found that the model's uncertainty is higher in the boundaries and lower in the center of the simulation domain.
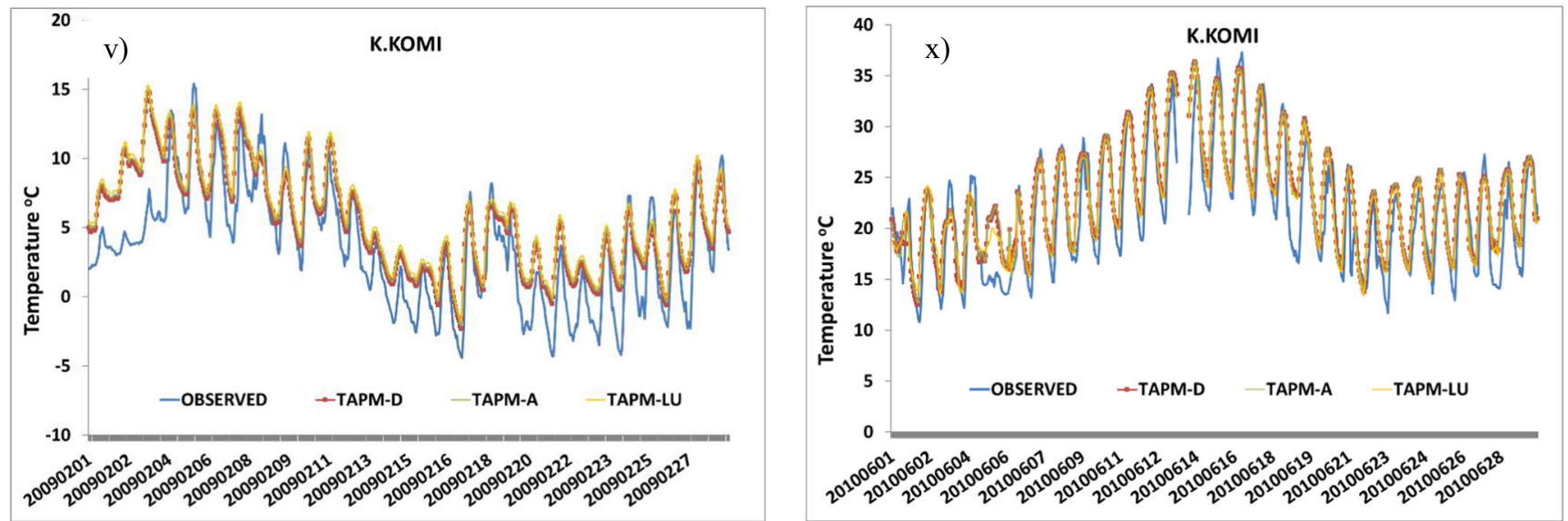

Fig. 6 (continued) 


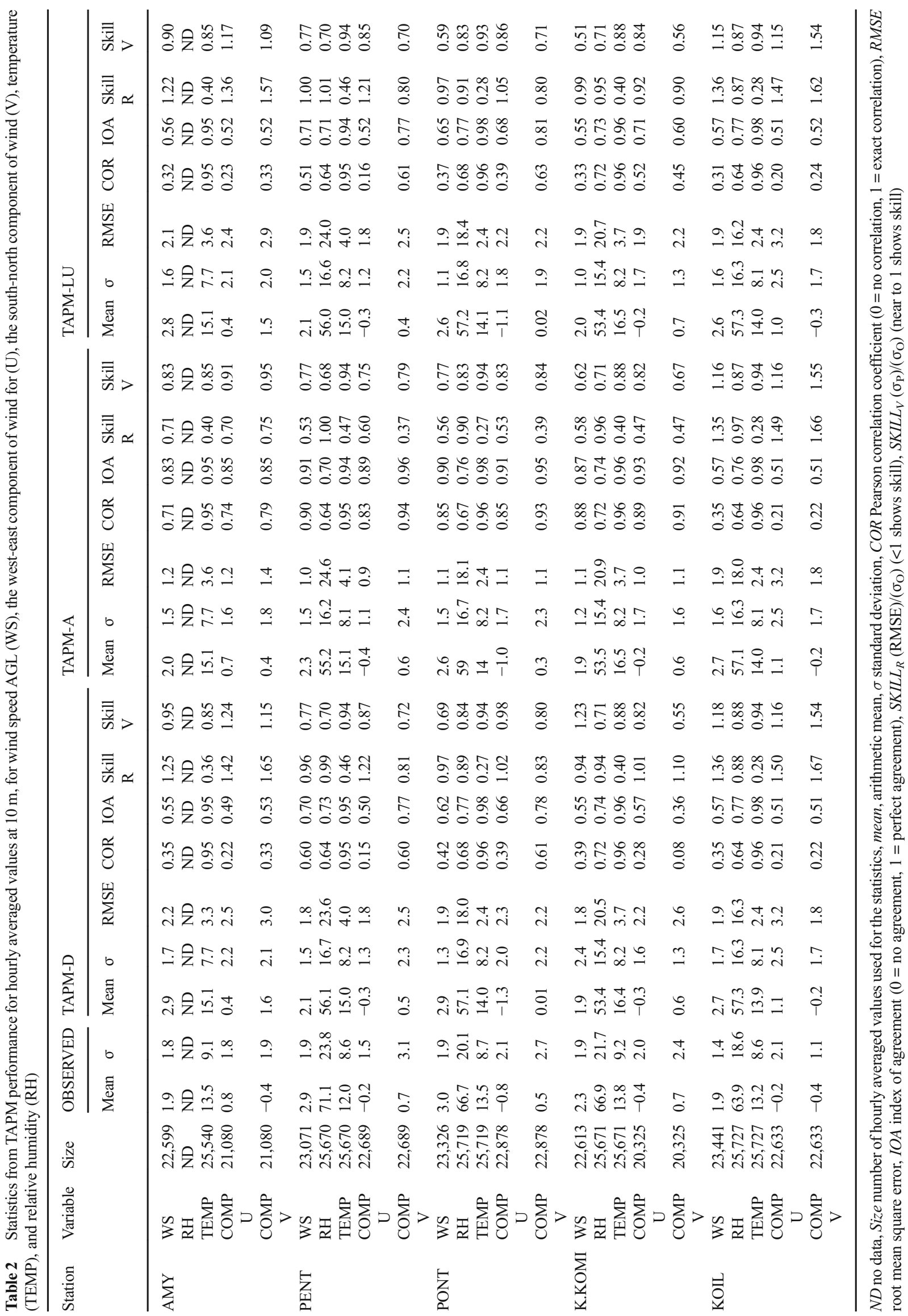




\subsection{TAPM predictions over lake breezes and mountain flows}

Local atmospheric circulations from lake/sea breezes and/or anabatic and katabatic flows can play an important role in the wind flow and consequently in the concentrations of air pollutants. As it was observed by earlier studies in the APKB, the artificial lake of Polifitos (Fig. 1) plays a critical role to the determination of concentration levels. This lake creates an easterly, southeasterly flow, which develops mainly during noon and afternoon hours and affects the concentrations of pollutants in the area (Triantafyllou 2001). This section examines TAPM performance in predicting the frequencies of such flows in a mountainous complex terrain, by comparing the observed and modeled frequencies of the wind. In particular, for the lake breeze mechanism, we examine the monitoring site of K.KOMI, which is near the lake, and for the mountain flows, the monitoring site of KOIL (see Fig. 1 for the exact location).

Considering the lake breeze, Fig. 7 shows the frequencies of the winds for the monitoring station of K.KOMI. TAPM-D calculates the variation of the prevailing NW flow, which has the same development pattern to the observations, with high frequencies during morning and night hours and a decline during the noon and early afternoon hours. At noon and afternoon hours as already mentioned above, eastern and southeastern flows develop in the area from the thermal circulation of the artificial lake of Polifitos. TAPM-D predicts the easterlies with lower frequency. Despite the capture of the time development of those flows, since those flows both in the observations and in the TAPM-D predictions appear at late morning until late afternoon hours, TAPM-D underestimates SE flows. Nevertheless, TAPM-D follows the patterns of $\mathrm{N}$ flow, since it predicts both the magnitude of the frequencies and the peak that occurs between 09:00-10:00. As far as the westerlies are concerned, TAPM-D predictions for the development of those winds differ from the observations. Those westerly flows are attributed to mountain Bourinos and since they differ from the observations; this fact explains well the above overprediction in temperature's extreme low values as it was discussed earlier (see Sect. 4.1). In the second simulation, TAPM-A predicts the main NW flow of the station, both in time and in frequency comparable to the observed values. In parallel, the wind frequencies in TAPM-A are predicted better than the TAPM-D simulation. The E flows are calculated better than the TAPM-D simulation, and generally, they have the
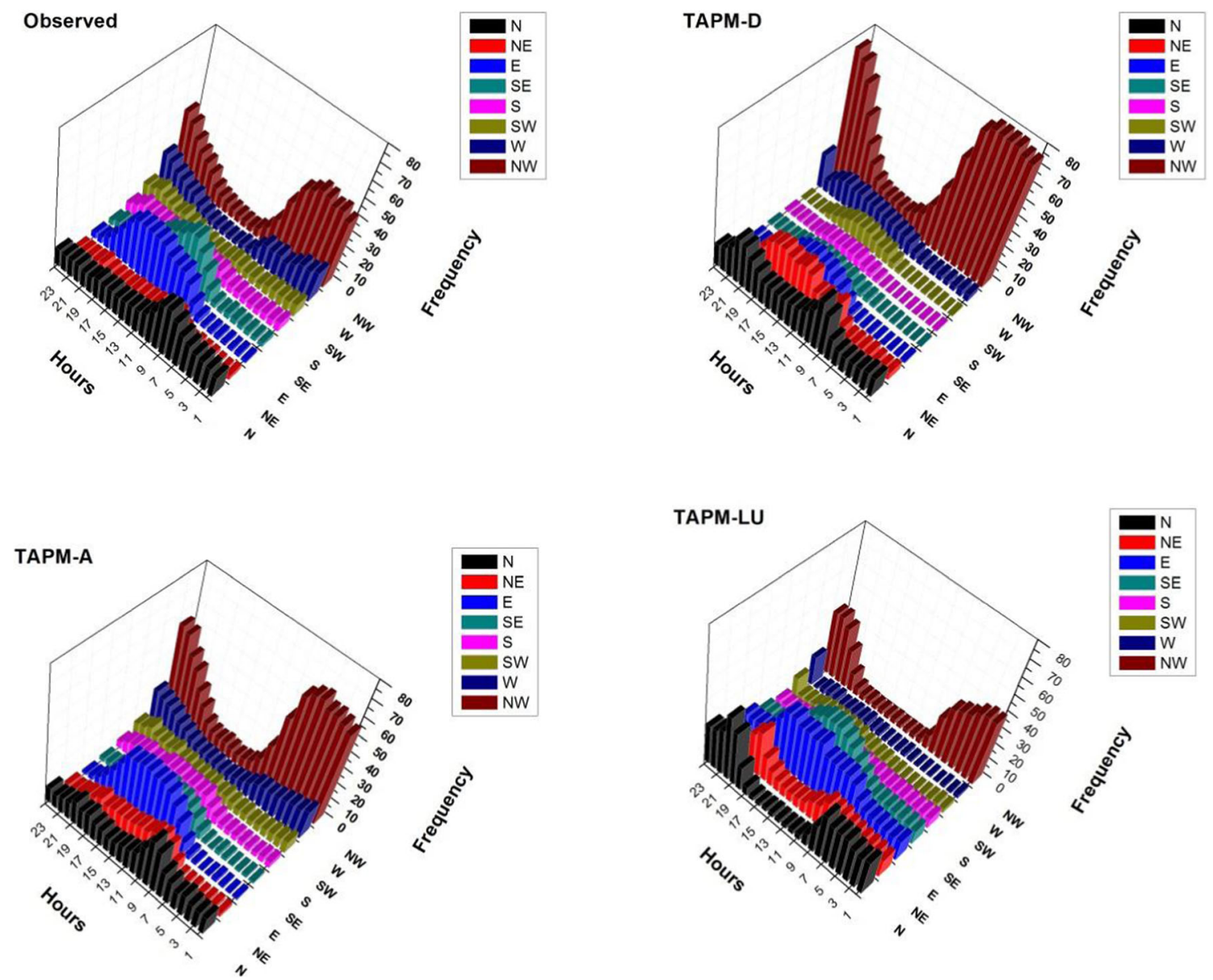

Fig. 7 Hourly variation frequencies of the wind flow in the station of K.KOMI for the entire data 
same behavior as the observations. These easterly flows develop between 13:00 at noon and 18:00 at the afternoon with scalar intensity both in the model and in the observations. As for the SE flows, TAPM-A simulates their time development and their frequencies better than TAPM-D; however, a minor difference in comparison to the observed frequency magnitude is evident. All other flow frequencies in TAPM-A are simulated with similar behavior and development as the observations. Finally, in the third simulation, TAPM-LU predicts the development of the dominant NW flow as the previous two simulations and similar to the observations. The frequencies of the easterlies are estimated better than the TAPM-D but not as good as in the TAPM-A and measurements. It is worth mentioning that the development of the SE flow in this simulation is calculated better; however, the peak in these flows has a longer duration compared to the measurement values. In general, it can be highlighted from the above results that the model is capable in predicting the development of the breeze coming from the artificial lake of Polifitos in all simulations, since it captures the shifts that occur in the prevailing NW and in $\mathrm{E}$ flows from the lake and vice versa.

Concerning the mountain flows, the station which might be affected the most is the station of KOIL. It was observed from the detailed frequencies that all three runs had the same behavior; in Fig. 8, the depicted wind frequencies are for the observed and the calculated by the TAPM-D values. The station's location is very idiomorphic due to the specific orography, and the prevailing W wind in the station (Fig. 4) comes by the terrain-forced rotations of the prevailing NW wind in the center of the APKB. This wind is very hard to be calculated by the model, and as it is evident from the detailed frequencies of the station, the model partly predicts this $\mathrm{W}$ flow as a NW flow. The local mountain flows in the station are attributed to the mountain Skopos with elevation of more than $900 \mathrm{~m}$ AGL, which is located southern from the station (see Figs. 1 and 2). Additionally, the mountain Vermio, which is located northeastern from the monitoring station with more than $2000 \mathrm{~m}$ of elevation, also influences the winds. The flows from the mountain Skopos have directions from SE, S, and $\mathrm{SW}$, and they develop according to the observations during late afternoon - early night hours, while the flows from the mountain Vermio have NE direction, and they develop during early to late afternoon hours (Fig. 8). The model, as shown from the Fig. 8, predicts the overall variation pattern and the development of the observations for the northeastern flows in the higher altitudes (mountain Vermio); however, it underestimates their frequency and misses the peak during the late afternoon hours. Additionally, TAPM captures the overall variation of southerly flows which are attributed to the mountain Skopos; however, it misses their general development, especially during late afternoon and early night hours. In general, it can be underlined that TAPM is able to capture the lake breeze development; however, it underestimates the development of some mountain orographic flows.

\subsection{Prediction of surface pollution}

As clarified earlier, the hourly averaged modeled $\mathrm{SO}_{2}$ concentrations are extracted from the innermost nested domain at the nearest grid point of each of the five monitoring stations and compared with average hourly observations. Despite the fact that the air pollution problem in the area is focused mainly on PM concentrations which exceed the air quality standards (Triantafyllou 2001, 2003), in this work, $\mathrm{SO}_{2}$ concentrations are analyzed. Given that the problem regarding the PM is more complicated, due to the large number of emission sources in the area (lignite power plants, open mines, quarries, agricultural activities, biomass burning, and even Saharan dust), the $\mathrm{SO}_{2}$ is actually used in the frame of the present study as a kind of "tracer gas" emitted from the stacks. This
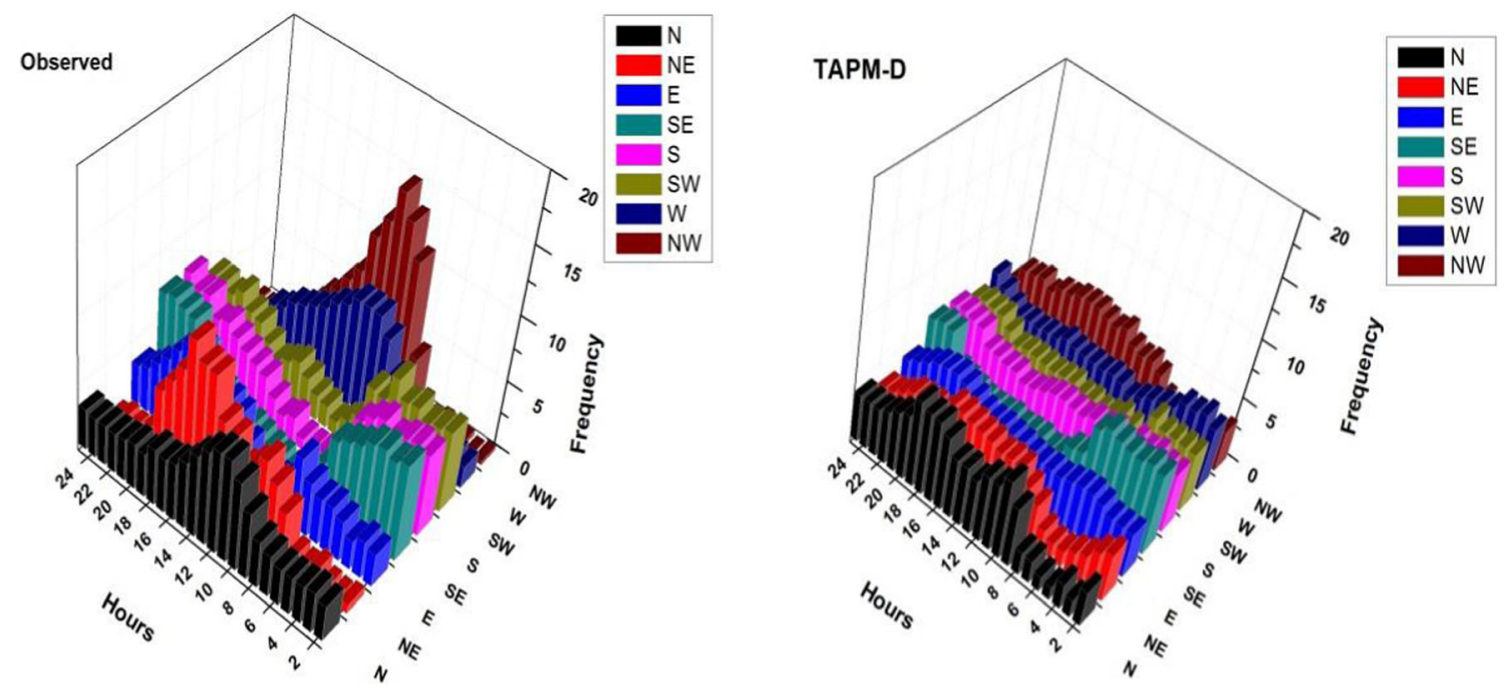

Fig. 8 Hourly variation frequencies of the wind flow in the station of KOIL for the entire data 
pollutant was also used for the evaluation of TAPM in other industrial areas of flat terrain (Hurley et al. 2008). The hourly values from which the observed concentrations of $\mathrm{SO}_{2}$ were less than or equal to $2.7 \mu \mathrm{g} / \mathrm{m}^{3}$ were excluded for the comparison. The above value is the detection limit of the model in $\mathrm{SO}_{2}$ concentrations (Luhar and Hurley 2004). All the remaining predicted and observed concentrations were grouped and then sorted, and therefore, there was no time correspondence between the two groups. The Quantile-Quantile plot in Fig. 9 depicts the sorted predicted concentrations against the sorted observed $\mathrm{SO}_{2}$ concentrations, in order to examine any bias over the value distribution. This plot is suitable according to Chang and Hanna (2004), because it quickly reveals biases at low or high concentrations, since it ranks each of the observed
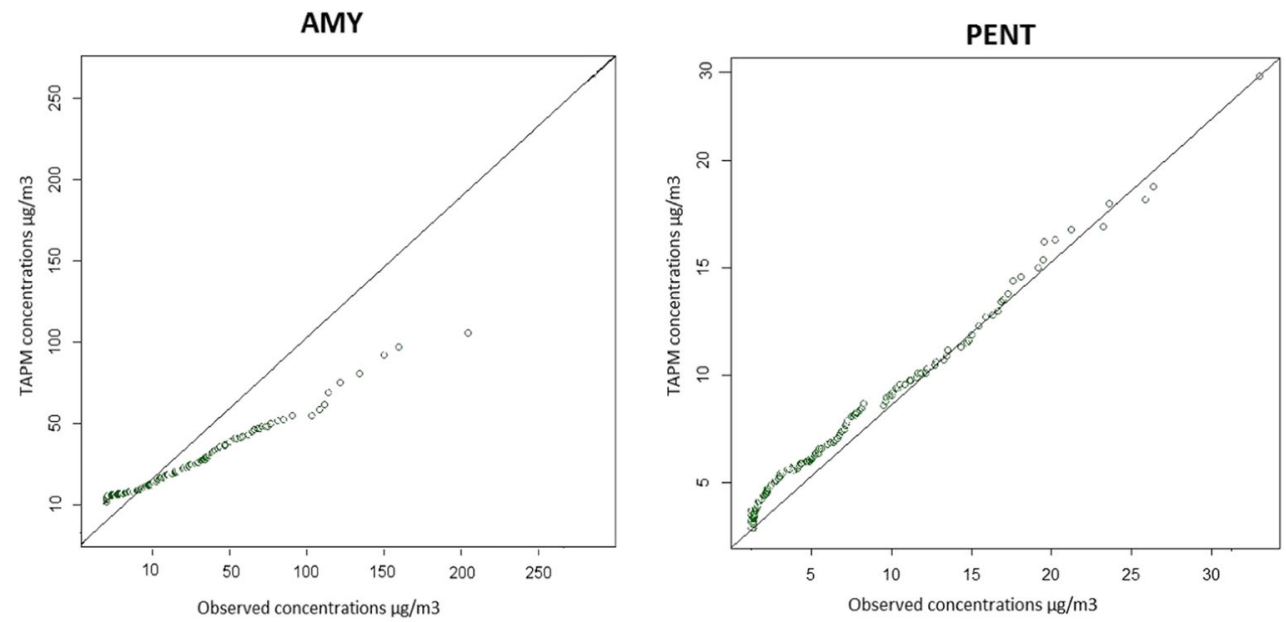

PONT
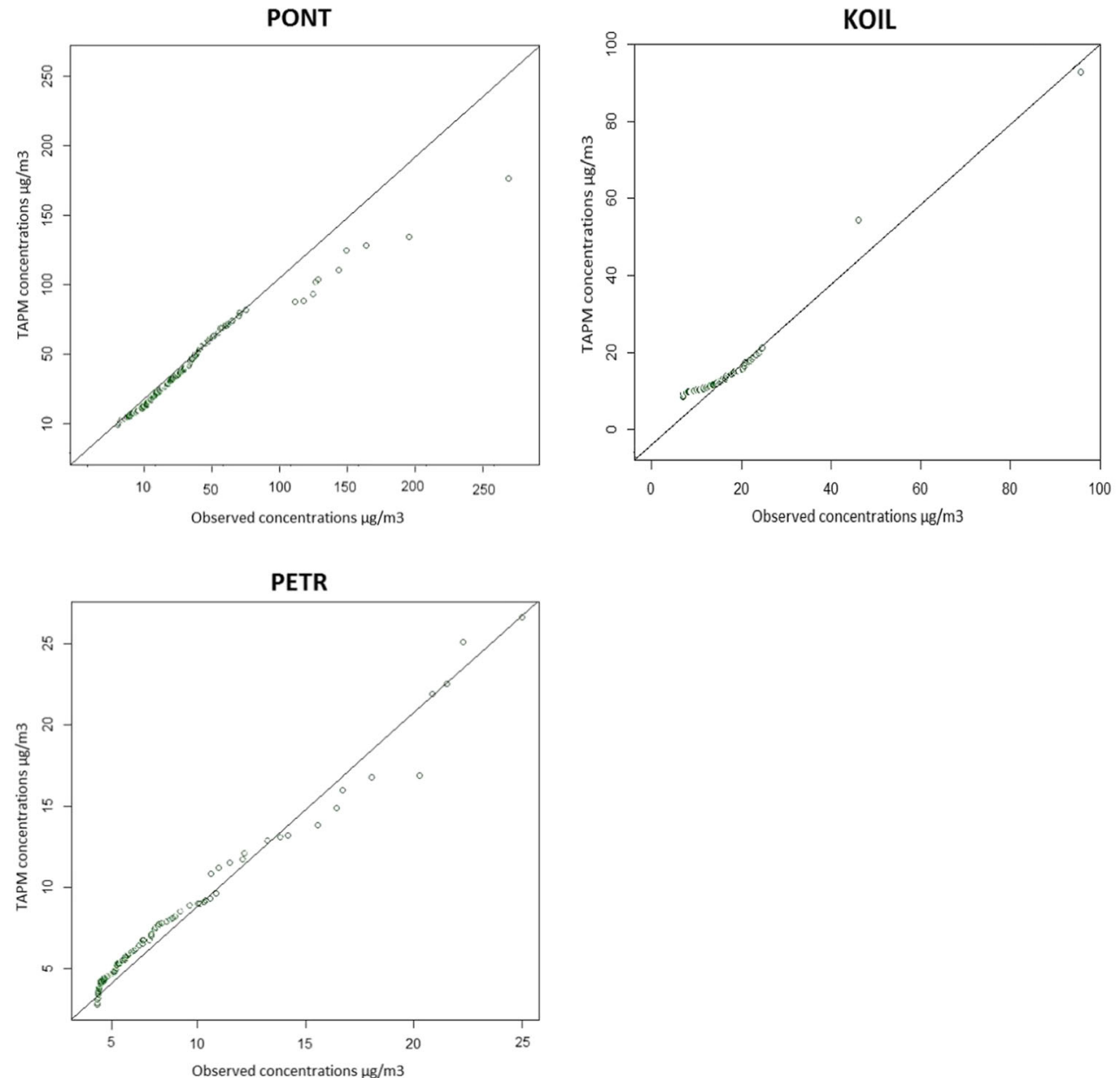

Fig. 9 Quantile-Quantile plots of TAPM predicted vs. observed $\mathrm{SO}_{2}$ concentrations for the stations of AMY, PENT, PONT, KOIL, and PETR 
Table 3 Model performance statistics for the hourly averaged $\mathrm{SO}_{2}$ concentrations

\begin{tabular}{llllllllll}
\hline & $\begin{array}{l}\mathrm{O}_{\text {mean }}(\mu \mathrm{g} / \\
\left.\mathrm{m}^{3}\right)\end{array}$ & $\begin{array}{l}\mathrm{P}_{\text {mean }}(\mu \mathrm{g} / \\
\left.\mathrm{m}^{3}\right)\end{array}$ & $\begin{array}{l}\sigma_{\mathrm{O}}(\mu \mathrm{g} / \\
\left.\mathrm{m}^{3}\right)\end{array}$ & $\begin{array}{l}\sigma_{\mathrm{P}}(\mu \mathrm{g} / \\
\left.\mathrm{m}^{3}\right)\end{array}$ & $\begin{array}{l}\text { Bias }(\mu \mathrm{g} / \\
\left.\mathrm{m}^{3}\right)\end{array}$ & IOA & COR & FB & FAC2 \\
\hline AMY & 6.2 & 2.9 & 7.4 & 3.0 & 3.34 & 0.37 & 0.15 & 0.72 & 0.47 \\
PENT & 2.6 & 1.6 & 2.7 & 3.4 & 1.03 & 0.46 & 0.21 & 0.48 & 0.62 \\
PONT & 3.6 & 2.9 & 10.7 & 9.1 & 0.71 & 0.51 & 0.30 & 0.21 & 0.81 \\
KOIL & 2.3 & 1.6 & 2.8 & 3.0 & 0.73 & 0.57 & 0.48 & 0.35 & 0.70 \\
PETR & 1.2 & 0.8 & 3.9 & 3.5 & 0.44 & 0.51 & 0.33 & 0.40 & 0.67 \\
\hline
\end{tabular}

and predicted data separately from the lowest to the highest. Thus, for example, the third lowest predicted concentration would be plotted versus the third lowest observed concentration. The plot indicates that the overall concentration distribution is generally good for all the stations across the simulated domain, apart from AMY, where an underprediction is illustrated, and PONT, where the underprediction occurs in the higher concentrations. Table 3 depicts the model performance statistics between the observed and predicted concentration levels for 2011, paired in both time and space, for the aforementioned monitoring stations in the meteorology section, while Fig. 10 shows the comparison of the RHC. According to the statistical measures (Table 3), for the station of AMY (located in the north boundaries of the basin), the model underpredicts the $\mathrm{SO}_{2}$ concentrations, a fact which is also shown by all other indices and the IOA $=0.37$. However, this underprediction of the model could be attributed to the PPS5 contribution (see Fig. 1), which is close to the border of the area of interest. This specific PPS5, which was not included in the simulations due to unavailable and uncertain emission rates, is consisted of an outdated technology and in a typical simulation case concerning the West Macedonia region, Trianafyllou et al. (2000) using a Lagrangian particle dispersion model coupled to a mesoscale prognostic model showed that pollutants were transported from this PPS5 to the south and consequently into the north part of APKB. For the station of PENT, the model predicts well the mean $\mathrm{SO}_{2}$ concentration, but in the overall prediction, a slight underestimation is evident for the concentration levels that is also verified by the $\mathrm{IOA}=0.46$. One possible reason for this slight underestimation of the model might be the site's location, since it is the second northern monitoring station after AMY station (Figs. 1 and 2), and a possible contribution from the PPS5 might result into this underprediction of the overall concentration levels. On the other hand, the model is able to predict the extreme $\mathrm{SO}_{2}$ concentrations for the station, as indicated by the RHC in Fig. 10, where the predicted and observed values are almost equal. For the station of PONT, the model also predicts well the mean concentration of $\mathrm{SO}_{2}$. The IOA is 0.51 , and the scores of FAC2 and FB show that the overall predictions of the concentration levels are fair. For the same station, the model underestimates the RHC concentrations. As already mentioned above, in the area and next to the power plant stations, there are many hectares of land which are covered by open-pit mining activities. Therefore, and since the station is between two PPSs (Fig. 1), a potential random episode which is probably caused by the trucks from a nearby traffic road of the open pit-mines might result into this difference. Instead of the K.KOMI station, where no $\mathrm{SO}_{2}$ concentrations were available, we compared the modeled $\mathrm{SO}_{2}$ concentrations for the station of PETR, which is located in about 8-km horizontal distance from the station of K.KOMI (Fig. 1) and is still under the influence of the lake breeze of Polifitos. The predictions for the station of PETR are well with $\mathrm{IOA}=0.52$. The model also predicts the mean and extreme concentrations for the same station, as indicated by Table 3 and Fig. 10, respectively. Regarding the station of KOIL, the model predicts well the mean and the overall $\mathrm{SO}_{2}$ concentrations of the station with IOA $=0.57$. Moreover, the RHC is also predicted well by TAPM with generally good agreement. Finally, although the overall performance of the model in predicting the $\mathrm{SO}_{2}$ concentrations for the region is considered good, it is still lower than the typical examples of simulation by TAPM from other regions (Hurley et al. 2003). We estimate that the uncertainties of the inputs such as emission rates (hourly instead of daily) and stacks exit velocity (averaged of 6 months), as well as the complexity of the region in the physiographic characteristics in conjunction with the open-pit mining activities (we updated land use in restored areas of the open-pit mines, not the main activities or the topography), are some possible reasons for this discrepancy.

\section{Robust Highest Concentration (RHC)}

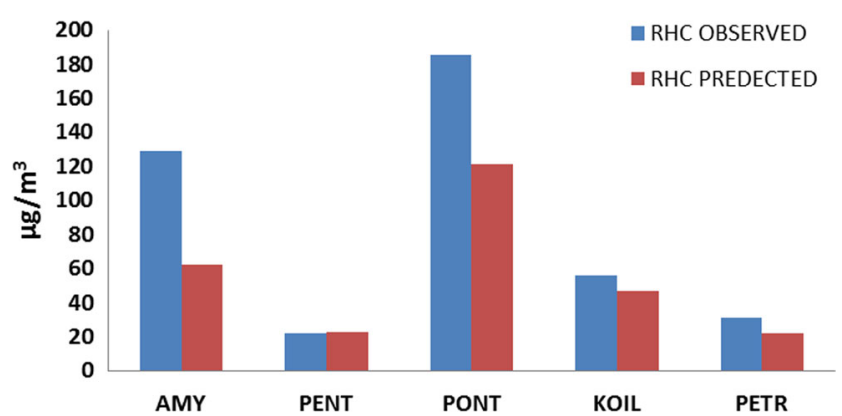

Fig. 10 Robust highest concentrations between modeled and observed data for all the monitoring stations 


\section{Conclusions}

The current study presented the performance and evaluation of the mesoscale prognostic meteorological and air pollution model TAPM in a mountainous complex terrain industrial area in Greece for a 3-year period (2009-2011), under different conditions.

For the meteorology, it was found that TAPM predicted well the surface temperature and relative humidity. However, TAPM underestimated the extreme low temperatures during winter and occasionally the low temperatures during summer. The biggest difference in extreme low temperatures (winter period) was observed in a site close to both a lake and a mountain. For the extreme high temperatures (summer period), the biggest difference was found in a site close to the highest mountain.

TAPM simulated fairly well the dominant surface wind flows across the domain. However, it overestimated the westerlies in the center of the simulation domain both with and without data assimilation. This result merits further investigation. Default predictions are fair and better for all the wind variables in the center of the simulation domain. Data assimilation, wherever used, significantly improved the performance of the model, both in the boundaries and in the center of the simulation domain. Land use updates were considered positive, since a significant improvement was evident, especially, for the boundary horizontal wind components.

The performance for the complex terrain local flows (lake breeze and mountain flows) showed that TAPM simulated the shifts which occurred between the development of the prevailing wind and the flows from the lake in all simulations. Default dataset underestimated the magnitude of the frequencies of the lake flows, while an improvement occurred in datasets with data assimilation and updated land use. Regarding the local mountain flows, TAPM captured the overall variation and the development of such flows attributed to higher altitudes, but it underestimated their frequency. Furthermore, TAPM underestimated the development of the mountain flows in the lower altitudes.

For the air pollution, TAPM predicted the mean and extreme values of the $\mathrm{SO}_{2}$ in the simulated domain, while the statistical measures showed fair agreement. TAPM's performance for the prediction of pollution is expected to be enhanced if more detailed/accurate data inputs of the pollution sources were available and were taken into consideration.

From the above concluding results, it can be recommended that TAPM can be used for operational year-long simulations without data assimilation in order to save time. However, the user should carefully choose the location of the outputs, since they are more sensitive in the boundaries of the simulated domain. Data assimilation is recommended for simulations of short duration or for case studies since they significantly improve the winds both in the center and in the boundaries of the simulated domain. Updated land use, in the applied extent, improves TAPM results and if combined with newly remote sensing observations, they can give augmented predictions. However, interesting is to see the combined use of updated land use cover and data assimilation, a configuration which requires much time in order to be build and it will be a forthcoming work.

Finally, evaluation and comparison with other prognostic models need to be made, in order to investigate the influence of a new soil texture, as well as the parameters of snow. Deep soil temperature and moisture based on experimental data must be evaluated, followed by a sensitivity analysis, while the emission inventories from potential attributed sources (open pit mine and transboundary power stations) will also be investigated.

Acknowledgements The authors would like to thank the Greek Power Public Corporation for providing the emission measurements from the stacks of the power plant stations, as well as data from their monitoring air quality network (Amyntaio, Pentavrysos, Pontokomi, K. Komi, Koilada and Petrana meteorological and $\mathrm{SO}_{2}$ data).

Open Access This article is distributed under the terms of the Creative Commons Attribution 4.0 International License (http:// creativecommons.org/licenses/by/4.0/), which permits unrestricted use, distribution, and reproduction in any medium, provided you give appropriate credit to the original author(s) and the source, provide a link to the Creative Commons license, and indicate if changes were made.

\section{References}

Aidaoui L, Triantafyllou AG, Azzi A, Garas SK, Matthaios VN (2014) Elevated stacks' pollutants' dispersion and its contribution to photochemical smog formation over a heavily industrial area. Air Quality, Atmosphere \& Health 8(Issue 2):213-227. doi:10.1007/ s11869-014-0300-9

Appel KW, Gilliam RC, Davis N, Zubrow A, Howard SC (2011) Overview of the atmospheric model evaluation tool (AMET) v1.1 for evaluating meteorological and air quality models. Environ Model Softw 26:434-443

Bennett ND, Croke BFW, Guariso G, Guillaume JHA, Hamilton SH, Jakeman AJ, Masili-Libelli S, Newham LTH, Norton JP, Perrin C, Pierce SA, Robson B, Seppelt R, Voinov AA, Fath BD (2013) Characterising performance of environmental models. Environ Model Softw 40:1-20

Chang CJ, Hanna RS (2004) Air quality model performance evaluation. Meteorog Atmos Phys 87:167-196

Cox W, Tikvart J (1990) A statistical procedure for determining the best performing air quality simulation. Atmos Environ 24A:2387-2395

De Meij A, Gzella A, Cuvelier C, Thunis P, Bessagnet B, Vinuesa JF, Menut L, Kelder HM (2009) The impact of MM5 and WRF meteorology over complex terrain on CHIMERE model calculations. Atmos Chem Phys 9:6611-6632

Graetz RD (1998) The terrestrial carbon pools of the Australian continent: an assessment of their size, dynamics, and tractability. Unpubl. Report to National Greenhouse Gas Inventory, Environment Australia. Department of Environment, Sport and Territories. CSIRO Earth Observation Center, Canberra $245 \mathrm{p}$ 
Hanna S (1989) Confidence limits for air quality model evaluations, as estimated by bootstrap and jackknife resampling methods. Atmos Environ 23:1385-1398

Hanna S, Chang J (2012) Acceptance criteria for urban dispersion model evaluation. Meteorog Atmos Phys 116:133-146

Hurley P (1994) PARTPUFF — a Lagrangian particle/puff approach for plume dispersion modelling applications. J Appl Meteorol 33:285294

Hurley P, Blockley A, Rayner K (2001) Verification of a prognostic meteorological and air pollution model for year-long predictions in the Kwinana region of Western Australia. Atmos Environ 35:18711880

Hurley P, Manins P, Lee S, Boyle R, Leung NY, Dewundege P (2003) Year-long, high-resolution, urban airshed modeling: verification of TAPM predictions of smog and particles in Melbourne, Australia. Atmos Environ 37:1899-1910

Hurley P, Physick W, Luhar A (2005) TAPM — a practical approach to prognostic meteorological and air pollution modeling. Environ Model Softw 20:737-752

Hurley P, Edwards M, Luhar A (2008) TAPM V4. Part 2: summary of some verification studies. CSIRO Marine and Atmospheric Research Paper No.26 October 2008

Lettau HH (1970) Physical and meteorological basis for mathematical models of urban diffusion processes. Proceedings of Symposium of Multiple-Source Urban diffusion Models, Chapel Hill, North Carolina, USA

Luhar A, Hurley P (2003) Evaluation of TAPM, a prognostic meteorological and air pollution model, using urban and rural point-source data. Atmos Environ 37:2795-2810

Luhar AK, Hurley PJ (2004) Application of a prognostic model TAPM to sea-breeze flows, surface concentrations and fumigating plumes. Environ Model Softw 19:591-601

Luhar AK, Hurley PJ (2012) Application of a coupled prognostic model to turbulence and dispersion in light-wind stable conditions, with an analytical correction to vertically resolve concentrations near the surface. Atmos Environ 51:56-66

Matthaios VN, Triantafyllou AG, Garas S, Krestou A, Leivaditou E (2016) Interactions between complicated flow-dispersion patterns and boundary layer evolution in a mountainous complex terrain during elevated $\mathrm{SO}_{2}$ concentrations. Meteorol Atmos Phys. doi:10. 1007/s00703-016-0480-y

Moussiopoulos N, Helmis CG, Flocas HA, Louka P, Assimakopoulos VD, Naneris C, Sahm P (2004) A modelling method for estimating transboundary air pollution in southeastern Europe. Environ Model Softw 19:549-558

Oke TR (1988) The urban energy balance. Prog Phys Geogr 12:471-508

Papalexiou S, Moussiopoulos N (2006) Wind flow and photochemical air pollution in Thessaloniki, Greece. Part II: statistical evaluation of European zooming Model's simulation results. Environ Model Softw 21:1752-1758

Pielke RA (1984) Mesoscale meteorological modelling. Academic Press, Orlando 612pp

Russell A, Dennis R (2000) NARSTO critical review of photochemical models and modeling. Atmos Environ 34:2283-2324

Samara C (2005) Chemical mass balance source apportionment of TSP in a lignite-burning area of western Macedonia, Greece. Atmos Environ 39:6430-6443

San Jose R, Stohl A, Karatzas K, Bohler T, James P, Perez JL (2005) A modelling study of an extraordinary night time ozone episode over Madrid domain. Environmental modeling \& Software 20:587-593

Seaman LN (2000) Meteorological modeling for air-quality assessments. Atmos Environ 34:2231-2259

Seaman NL, Stauffer DR, Lario AM (1995) A multiscale fourdimensional data assimilation system applied in the San Joaquin
Valley during SARMAP. Part I: modelling design and basic performance characteristics. J Appl Meteorol 34:1739-1761

Shiang-Yuh W, Krishnan S, Zhang Y, Aneja V (2008) Modeling atmospheric transport and fate of ammonia in North Carolina - part I: evaluation of meteorological and chemical predictions. Atmos Environ 42:3419-3436

Silvester SA, Lowndes IS, Hargreaves DM (2009) A computational study of particulate emissions from an open pit quarry under neutral atmospheric conditions. Atmos Environ 43:6415-6424

Sokhi RS, San Jose R, Kitwiroon N, Fragkou E, Perez JL, Middleton DR (2006) Prediction of ozone levels in London using the MM5CMAQ modelling system. Environ Model Softw 21:566-576

Srinivas CV, Venkatesan R, Yesubabu V, Nagaraju C, Venkatraman B, Chellapandi P (2011) Evaluation of the operational atmospheric model used in emergency response system at Kalpakkam on the east coast of India. Atmos Environ 45:7423-7442

Tominaga Y, Stathopoulos T (2013) CFD simulation of near-field pollutant dispersion in the urban environment: a review of current modeling techniques. Atmos Environ 79:716-730. doi:10.1016/j. atmosenv.2013.07.028

Trianafyllou AG, Vosniakos F, Charalabidis G, Papadakis N (2000) On the pollutant concentrations and dispersion in West Macedonia region, Greece. Fresenius Environ Bull 9:023-029

Triantafyllou AG (2000) Patterns and concentrations of PM10 in a mountainous basin region. J Air Waste Manage Assoc 50(6):1017-1022. doi:10.1080/10473289.2000.10464146

Triantafyllou GA (2001) PM10 pollution episodes as a function of synoptic climatology in a mountainous industrial area. Environ Pollut 112:491-500

Triantafyllou GA (2003) Levels and trends of suspended particles around large lignite power stations. Environ Monit Assess 89:15-34

Triantafyllou GA, Kassomenos P (2002) Aspects of atmospheric flow and dispersion of air pollutants in a mountainous basin. The Science of Total Environment 297:85-103

Triantafyllou AG, Helmis CG, Asimakopoulos DN, Soilemes AT (1995) Boundary layer evolution over large and broad mountain basin. Theoritical and Applied Climatology 52:19-25

Triantafyllou AG, Krestou A, Hurley P, Thatcher M (2011) An operational high resolution local scale meteorological and air quality forecasting system for Western Macedonia, Greece: some first results. Proceedings of the 12 th International Conference on Environmental Science and Technology, Rhodes Island, Greece, pp. 1904-1911

US EPA (1995) User guide for the industrial source complex (ISC3) dispersion models, user instructions, vol 1. US Environmental Protection Agency, EPA -454/B-95-003a

US EPA (2004) User's guide for the AMS/EPA regulatory modelAERMOD. Environmental Protection Agency, EPA-454/B-03-001

Willmott C (1981) On the validation of models. Phys Geogr 2:183-194

Zawar-Reza P, Kingham S, Pearce J (2005a) Evaluation of a year-long dispersion modeling of PM10 using the mesoscale model TAPM for Christchurch, New Zealand. Sci Total Environ 349:249-259

Zawar-Reza, P., Titov, M. and Sturman, A.P., 2005b. Dispersion modelling of PM10 for Christchurch, New Zealand: an intercomparison of performance between mesoscale model (MM5) and the air pollution model (TAPM). Hobart, Australia: 17th International Clean Air and Environment Conference, 3-6 May 2005

Zhang Y, Cheng SH, Chen YS, Wang WX (2011) Application of MM5 in China: model evaluation, seasonal variations, and sensitivity to horizontal grid resolutions. Atmos Environ 45:3454-3465

Zoras S, Triantafyllou AG, Hurley PJ (2007) Grid sensitivity analysis for the calibration of a prognostic meteorological model in complex terrain by a screening experiment. Environ Model Softw 22:33-39 